\title{
NMDA Receptor Currents Suppress Synapse Formation on Sprouting Axons In Vivo
}

\author{
Matthew T. Colonnese, ${ }^{1,2}$ Jian-Ping Zhao, ${ }^{1}$ and Martha Constantine-Paton ${ }^{1}$ \\ ${ }^{1} \mathrm{McG}$ overn Institute for Brain Research, Departments of Biology and Brain and Cognitive Sciences, Massachusetts Institute of Technology, Cambridge, \\ Massachusetts 02139, and 2Interdepartmental Neuroscience Program, Yale University, New Haven, Connecticut 06520
}

\begin{abstract}
NMDA receptors (NMDARs) play an important role in the structural maintenance and functional strength of synapses. The causal relationship between these anatomical and functional roles is poorly defined. Using quantitative confocal microscopy, synaptic vesicle immunoreactivity, and differential label of retinal projections, we measured axon volume and synapse density along ipsilateral retinal axons (ipsi axons) sprouting into the superficial visual layers of the superior colliculus (sSC) deafferented by a contralateral retinal lesion (a scotoma) $8 \mathrm{~d}$ earlier. When retinal lesions were made at postnatal day 6 (P6), glutamatergic synaptic currents on neurons within the scotoma were significantly reduced. Both ipsi axon sprouting and synapse density were increased by chronic D-AP-5 antagonism of NMDARs. Conversely, ipsi axon sprouting and synapse density were reduced by chronic exposure to the agonist, NMDA, known to functionally depress glutamate transmission in this system. After P11 lesions, however, NMDAR blockade had no effect on sprouting or synapse density. Developmental changes in NMDAR current kinetics could not account for this difference in the structural effects of NMDAR function. Also, synaptic current frequencies within the scotoma were not affected after the P11 lesions. The corticocollicular projection matures during the P11 survival interval and, as indicated by previous work, it is a source of competition for synaptic space and probably of maintained activity in the older sSC. Thus, our results suggest that during early development, NMDAR currents predominantly destabilize nascent synapses. As the neuropil matures, however, competition for synaptic space suppresses axon sprouting and synapse formation regardless of NMDAR function.
\end{abstract}

Key words: development; superior colliculus; potentiation; depression; lesion; synapse elimination

\section{Introduction}

The NMDA receptor (NMDAR) has been implicated in the competitive rearrangement of afferent connections that organize developing neural circuits. It is generally believed that large NMDAR currents, produced by correlated activity, stabilize contacts and the axon branches that support them, whereas smaller NMDAR currents, produced by uncorrelated actively, destabilize contacts and cause retraction of terminals (Bear and Rittenhouse, 1999). The presumed physiological correlates of these effects are changes in AMPA-sensitive glutamate receptor (AMPAR) currents resulting from NMDAR-dependent long-term potentiation and long-term depression (LTD) (Malinow and Malenka, 2002). A close relationship between cholinergic synaptic effectiveness and terminal survival has been observed at the vertebrate neuromuscular junction (Colman et al., 1997), but little structural evidence of such a relationship between NMDAR function and synaptic survival has been made in the developing CNS.

Previously, we used small lesions in one retina to denervate a region of the superior colliculus (sSC) and to study the interac-

Received May 7, 2004; revised Dec. 19, 2004; accepted Dec. 21, 2004.

This work was supported by National Institutes of Health Grant EY06039 to M.C.-P. We thank Dr. Frank Miskevich for assistance in writing NIH Image macros.

Correspondence should be addressed to Dr. Matthew T. Colonnese, Massachusetts Institute of Technology, Building 68-380, 77 Massachusetts Avenue, Cambridge, MA 02139-4307. E-mail: mcolonne@mit.edu.

D0I:10.1523/JNEUROSCI.4063-04.2005

Copyright $\odot 2005$ Society for Neuroscience $\quad$ 0270-6474/05/251291-13\$15.00/0 tion between afferent competition and NMDAR function in determining the sprouting of converging projections (Colonnese and Constantine-Paton, 2001). The axons of ipsilateral retinal ganglion cells (ipsi axons) normally terminate sparsely in the top layers of the sSC (Lund, 1965); however, partial or complete lesion of the contralateral retinal projection results in sprouting of the ipsi axons into the deafferented region (Lund and Lund, 1973; Finlay et al., 1979). Chronic NMDAR blockade can facilitate this sprouting, although it cannot induce it, when the lesion is made on postnatal day 6 (P6). However, the same treatment does not facilitate sprouting after a P11 lesion unless the late-developing (Lopez-Medina et al., 1989) competition from the corticocollicular projection is removed (Colonnese and Constantine-Paton, 2001). Because NMDAR blockade does not disrupt AMPA receptor function in the sSC (Colonnese et al., 2003), the effects of the blockade are directly the result of eliminating NMDAR currents. In the present study, our retinal lesion protocol is combined with an analysis of the density of synapses made by the sprouting ipsi axons to determine whether the extra sprouting induced by NMDAR blockade is accompanied by changes in the density of synaptic contacts along the sprouted retinal axons. This work differentiates between two opposite scenarios for the relationship between NMDAR blockade and its documented effect on increasing axon terminal area: (1) that receptor blockade reduces synaptic stabilization and encourages sprouting to establish sufficient contacts, or (2) that it increases synapse survival and these 
contacts subsequently allow more branch retention. This work supports the second explanation and suggests that NMDARs are actively reducing synapse formation or retention. Treatment with the agonist NMDA supports the hypothesis that synaptic elimination is the eventual result of persistent NMDARdependent synaptic depression (Bear and Rittenhouse, 1999).

\section{Materials and Methods}

Animals and materials. Timed pregnant Sprague Dawley rats were acquired from Charles River Laboratories (Southbridge, MA) or Taconic Animal Laboratories (Germantown, NY) and housed in a $12 \mathrm{~h}$ light/dark cycle. The inert ethylene-vinyl acetate copolymer Elvax-40W (DuPont, Billerica, MA) was prepared with 2-amino-5-phosphonopentanoic acid (AP-5) as reported previously (Cline and Constantine-Paton, 1989; Smith et al., 1995; Colonnese and Constantine-Paton, 2001; Colonnese et al., 2003) or with NMDA as reported previously (Aamodt et al., 2000; Shi et al., 2001). Control Elvax for antagonist experiments contained only the inactive isomer L-AP-5; for the NMDA experiments, only vehicle (water) was added. We previously estimated (Colonnese and Constantine-Paton, 2001) the concentration of D-AP-5 in the sSC to be above $20 \mu \mathrm{M}$ at all times and in the $100 \mu \mathrm{M}$ range during the first few days after implantation. The concentration of NMDA was estimated at above $5 \mu \mathrm{M}$ at all times and in the $20 \mu \mathrm{M}$ range for the first few days after implantation.

Surgery. Elvax sections were implanted on various days using the method described by Simon et al. (1992). Under anesthesia, the scalp and skull were retracted, and the Elvax slab was positioned over the sSC, the front edge tucked under the occipital cortex. Anesthesia was provided by inhaled 1-2\% isoflurane (1-chloro-2,2,2-trifluoroethyl difluoromethyl ether). A surgical plane of anesthesia was confirmed by a lack of response to toe pinch and monitoring for rapid increases in breathing rate. Sutures and tissue adhesive (Vetbond; 3M Animal Care Products, St. Paul, MN) were used to close the incision.

For eye lesions, pups were anesthetized and the left eye was opened with blunted iris scissors. The eyelids were retracted manually, and the lesion was made by insertion of a number 11 scalpel blade through the sclera, severing the axons of retinal ganglion cells lying at the temporal pole dorsal to the incision located $\sim 2 \mathrm{~mm}$ from the ciliary margin. For anterograde tracing of the retina, the cholera toxin B subunit (CTB) conjugated to Alexa 488 or Alexa 546 was used (Molecular Probes, Eugene, OR). Two days before they were killed, pups were anesthetized, and a small hole was made in the cornea with a 28 ga needle through which a Hamilton syringe (Hamilton, Reno, NV) outfitted with a 31 ga needle was used to inject $5 \mu \mathrm{l}$ of a solution of $0.2 \%$ CTB, $1 \%$ dimethyl-sulfoxide in PBS into the vitreous.

Pups were anesthetized and killed by transcardial perfusion of PBS followed by $4 \%$ paraformaldehyde in $0.1 \mathrm{~m}$ phosphate buffer, $\mathrm{pH}$ 7.2. The midbrain was removed and postfixed overnight at $4^{\circ} \mathrm{C}$. Animals with misplaced Elvax or damage to the sSC were excluded from additional analysis. The midbrain was photographed in whole-mount epifluorescence to visualize the dorsal midbrain optic targets. Pups with a lightly or incompletely labeled projection from the unlesioned eye were excluded from additional analysis. Previous work with this procedure has shown that deafferented regions that occupy between 7 and $35 \%$ of the sSC show no significant correlation between size and sprouting density (Colonnese and Constantine-Paton, 2001). Therefore, two animals with a scotoma that occupied $<7 \%$ of the sSC were excluded; none exceeded $35 \%$.

Immunohistochemistry. The midbrain blocks were embedded in 3.5\% low melting point agarose and $8 \%$ sucrose in PBS and cut in coronal section, $\sim 30 \mu \mathrm{m}$ thick, on a vibratome. Sections were preincubated for $1 \mathrm{~h}$ in $0.5 \%$ Triton X-100/4\% horse serum in PBS and then in the same solution plus primary antibody (monoclonal to synaptophysin, $6 \mu \mathrm{g} / \mathrm{ml}$, Sigma, St. Louis, MO; monoclonal to synapsin- $1,2 \mu \mathrm{g} / \mathrm{ml}$, Chemicon, Temecula, CA) or polyclonal to GAD 65/67 (14 $\mu \mathrm{g} / \mathrm{ml}$; Sigma) overnight at $4^{\circ} \mathrm{C}$. For double labeling of synaptophysin and glutamate receptor subunit 1 (GluR1) (polyclonal; $2 \mu \mathrm{g} / \mathrm{ml}$; Chemicon) or GluR2 (same as GluR1), no Triton X-100 was added during incubation. Fluorescently labeled (cyanine-5, Jackson ImmunoResearch, West Grove, PA; Alexa 633 or Alexa 546, Molecular Probes) secondary antibodies were used for visualization after mounting on glass slides in an aqueous, hardening, mounting media (Fluoromount; Electron Microscopy Sciences, Fort Washington, PA).

Microscopy. Confocal microscopy was performed on a Nikon (Tokyo, Japan) PCM 2000 controlled by the Compix (Cranberry Township, PA) software package running on a Pentium-based personal computer (Intel, Santa Clara, CA). Image analysis was performed using the public domain NIH Image program (available at http://rsb.info.nih.gov/nih-image/). For the montage image of whole-mount sSC, a $10 \times$ objective was used to acquire, in a grid pattern, volume stacks $150 \mu \mathrm{m}$ deep. Montages were constructed in Adobe Photoshop (Adobe Systems, San Jose, CA) using brightest point projections of the volume stacks. Higher-power images of the coronal sections for quantification of sprouting were acquired with a $20 \times$ Plan Fluor objective for a pixel size of $0.06 \mu \mathrm{m}^{2}$ in plane and an out-of-plane resolution of 1-2 $\mu \mathrm{m}$. For high-resolution images of synaptic puncta, a $60 \times 1.40$ numerical aperture objective was used to acquire images with a pixel size of $0.01 \mu \mathrm{m}^{2}$ in plane and $\sim 0.30 \mu \mathrm{m}$ out of plane. Laser power, gain, and black level were carefully modulated to remove any fluorophore bleed-though between channels. These parameters were kept constant for a complete experiment that included all control and experimental pups in a litter. Within litters, the imaging of pups from each treatment group was interdigitated to reduce any effects of a slow shift in laser alignment or power. The identities of all sections were coded, so all microscopy and computer analyses were performed blind to the treatment group.

Quantification of sprouting. Quantitative analysis of retinal axon sprouting was as described previously (Colonnese and ConstantinePaton, 2001). Three sections were chosen from each animal: the first, $\sim 400 \mu \mathrm{m}$ from the rostral edge, and every other section thereafter (i.e., sections $1,3,5)$. Two micrographs were taken from each section: the first outside the scotoma and at least $500 \mu \mathrm{m}$ from the medial edge, and the second within the scotoma and at least $200 \mu \mathrm{m}$ from the lateral edge (see Fig. $1 A c, A d)$. Thus, approximately the same six regions were sampled in each animal. The density of the ipsilateral retinal projection was calculated for each micrograph by creating a binary image with a threshold value chosen so that only pixels from in-focus fluorescence were retained. An absolute intensity threshold was set after examination of multiple pups in a litter and was maintained for all animals in that litter. This set threshold was approximately sixfold greater than the level of tissue autofluorescence, but the exact fold increase varied between animals and litters because of small differences in baseline autofluorescence.

The sSC, where the contralateral retinal projection terminates, consists of three laminas: a subpial stratum zonale (SZ), a deeper stratum griseum superficiale (SGS), and the stratum opticum (SO). The SO lies below the latter two layers and is sparsely populated by neurons but contains the afferent collicular axons and most of the normal ipsilateral retinal axon projection. To identify the region of interest (ROI) for sprouting ipsi axons in a given confocal micrograph, the contralateral projection was used as a guide. The middle and upper SGS and SZ were defined for each $z$-section. The density of ipsi-labeled pixels was measured within the ROI. This number was designated the "axon density," and it is an objective estimate of the innervation density of the ipsilateral retinal ganglion cell axons within the ROI.

Therefore, for each animal, we generated three pairs of axon density measurements: one inside the scotoma and one outside the scotoma for each of three sections. Thus, there was an internal control for each position along the rostrocaudal axis. To estimate the additional ipsilateral axon density caused by sprouting within the lesion, we calculated an "increased axon density" for each section by subtracting the axon density of the frame outside the scotoma (Out) from the axon density of the frame inside the scotoma (In). All litters were divided into the following two groups: experimental and control. After data collection, the increased axon density of each section was divided by the average value of the increased axon densities in the sections taken from the control pups in the same litter. Therefore, the equation for the sprouting index for each section is as follows: (In $)_{X}-(\text { Out })_{X} /\left(\Sigma\left[(\text { In })_{X}\right.\right.$ control $\left.\left.(\text { Out })_{\mathrm{Xcontrol}}\right] / N_{\text {control }}\right)$, where $(\mathrm{In})_{\mathrm{X}}$ and $(\text { Out })_{\mathrm{X}}$ are the axon densities for a given section $\mathrm{X}$, and $N_{\text {control }}$ is the number of control sections. The 
subset of axon densities from control animals is denoted (In) $\mathrm{Xcontrol}$ and (Out) Xcontrol $_{\text {. }}$

Quantification of synaptic density. Two sections per animal with spacing similar to those used for the sprouting analysis were retained for immunohistochemistry. All immunohistochemistry was performed in single batches for an entire litter; all imaging was completed within $2 \mathrm{~d}$ for each litter. In each section, two regions from inside the scotoma were chosen for imaging. With the investigator blind to synaptic stain, each section was scanned for regions of significant ipsilateral axon arbor density. This was necessary because the low density of arbor in many frames, especially at P11, made quantification of synaptic density impossible if regions of high-axon density were not selected. The dorsal edge of each region was within $10 \mu \mathrm{m}$ of the dorsal surface. Within each region, a stack of confocal images was taken from a $102 \times 102 \times 4 \mu \mathrm{m}$ volume of tissue at $0.25 \mu \mathrm{m}$ intervals. The first image was $4 \mu \mathrm{m}$ from the cut edge of the slice. Thus, a total of four volumes within the scotoma were studied from each sSC. The depth of these volumes was selected to be superficial enough to contain constant and bright synaptophysin label but to be deep enough that artifacts from the cut surface of the slice were not visible.

The basic design of the synaptic analysis was to count, using an optical dissector method (Gundersen, 1986), instances of overlap of retinal terminals and synaptic stain that met a minimum size criterion. A $3 \times 3$ pixel low-pass filter was applied to each image. For analysis of the synaptic immunostain, a linear histogram stretch was applied to each section to enhance contrast to equalize intensity differences resulting from tissue depth and photobleaching. This stretch was never $>30 \%$. An intensity threshold was chosen before the data analysis by visual examination of a number of micrographs from different animals within the litter to determine the intensity of in-focus fluorescence versus background and outof-focus fluorescence. A threshold of four SDs above the median intensity of the sections in a volume resulted in reliable exclusion of background. The median intensity of the slice is primarily a result of autofluorescence and did not change significantly with treatment. For axon terminals, which were more clearly separable from background and showed no change in intensity from depth or bleaching, a threshold of five SDs above baseline was chosen after examination of multiple sections.

For both the retinal axons and synaptic stain, the number of pixels above threshold was counted in each $\mathrm{z}$-section in each volume and added together to get a density for that region of neuropil. In addition, for each $\mathrm{z}$-section, an image that showed only the pixels occupied by both retinal terminals and synaptic stain was generated. The number of such pixels in each section was added together to generate a total number of "overlapped pixels" for each sampled volume. However, we were interested primarily in determining the number of presynaptic elements in the tissue, not just the total volume of vesicle accumulations within each axon volume. Therefore, in a given z-series, to count the number of presumptive presynaptic elements, termed synapses here, contiguous clusters of overlapped pixels larger than $0.16 \mu \mathrm{m}^{2}$ (for synaptophysin or GAD65/67 stain) or $0.10 \mu \mathrm{m}^{2}$ (for synapsin 1) were identified in the images of overlapped pixels. These sizes were previously chosen by visual inspection of stained sections to be a conservative minimal size. The chosen sizes helped to eliminate accidental overlap of axons and synaptic stain and were still significantly smaller than the presynaptic specializations in the sSC at this age (Warton and McCart, 1989). To determine the number of puncta in the volume, an optical dissector (Gundersen, 1986) was performed on the overlap micrographs. Sequential z-sections were examined, and only the first incidence of each puncta was counted. Puncta appearing in the first section were not included. Thus, each sampled volume generated four measurements: (1) the volume of ipsilateral retinal arbor, (2) the volume of synaptic stain, (3) the number of overlapped pixels, and (4) the number of synapses. The latter two measures were normalized for the volume of retinal arbor.

All statistics used one-tailed Student's $t$ tests for unequal variance performed on Microsoft Excel (Microsoft, Seattle, WA) between experimental animals and the appropriate controls. All data are reported as average \pm SEM. Post hoc calculations of power $(1-\beta)$ were made for a one-sided unequal variance $t$ test using the University of California Los
Angeles Department of Statistics Power Calculator (available at http:// rsb.info.nih.gov/nih-image/ and http://calculators.stat.ucla.edu/pc/ normal/n-2-unequal/). The $p$ value, as determined by $t$ test or 0.05 (whichever was higher), was used for significance level.

Electrophysiology. In the pups used to generate slices for whole-cell recording, retinal lesions and anterograde labeling were performed as described above, but only the lesioned eye was injected with CTB to localize the scotoma. Pups were anesthetized with isoflurane and killed by decapitation. The diencephalon and midbrain were placed in cold artificial CSF (ACSF) containing the following (in $\mathrm{mm}$ ): $117 \mathrm{NaCl}, 3$ $\mathrm{MgCl}_{2}, 4 \mathrm{KCl}, 3 \mathrm{CaCl}_{2}, 1.2 \mathrm{NaHPO}_{4}, 26 \mathrm{NaHCO}_{3}$, and 16 glucose saturated with $95 \% \mathrm{O}_{2}-5 \% \mathrm{CO}_{2}$ to a final $\mathrm{pH}$ of 7.4. The tissue was cut on a vibratome. Recordings were made from $300-400 \mu \mathrm{m}$ parasagittal slices of the midbrain maintained at room temperature $\left(22-24^{\circ} \mathrm{C}\right)$ and perfused with ACSF at $4 \mathrm{ml} / \mathrm{min}$. At least $1 \mathrm{~h}$ elapsed between cutting and recording from the slices. Before recording, each slice was examined with epifluorescence to determine the location of the scotoma. Neurons were selected so that they alternated between inside and outside the scotoma and were targeted for recording under visual control using infrared differential interference contrast optics. Whole-cell recordings were restricted to neurons in the middle and lower region of the stratum griseum superficiale.

Recording procedures have been presented previously (Shi et al., 1997). Borosilicate glass (World Precision Instruments, Sarasota, FL) patch electrodes with tip resistances of 5-10 $\mathrm{M} \Omega$ were filled with a solution containing the following (in mM): 122.5 Cs-gluconate, $17.5 \mathrm{CsCl}, 10$ HEPES (CsOH), 0.2 NaEGTA, 2 MgATP, 0.3 NaGTP, 8 NaCl. Cells had resting potentials between -45 and $-58 \mathrm{mV}$. All data included here are from recordings with seal resistances of 3-4 G $\Omega$ and series resistances of $<30 \mathrm{M} \Omega$; neither changed $>10 \%$ over the course of the experiment. Signals were recorded using an Axopatch 200B integrating patch-clamp amplifier, interfaced (Digidata 1322A; Axon Instruments, Foster City, CA) with a Pentium-based computer (Intel) that stored the data and provided on-line response display and off-line data analysis. Sampling was at $10 \mathrm{kHz}$, and filtering was at $5 \mathrm{kHz}$. pClamp 8.1 (Axon Instruments) and Mini Analysis Program (Synaptosoft, Decatur, GA) were used to acquire and analyze data.

Spontaneous NMDAR (sNMDAR), AMPAR, and $\mathrm{GABA}_{\mathrm{A}} \mathrm{R}$ current amplitudes were measured from the noise midline and were at least two times baseline noise (one-half the peak-to-peak amplitude, $\sim 2 \mathrm{pA}$ ). Frequencies of these spontaneous currents for each cell were obtained by randomly selecting intervals of at least $3 \mathrm{~min}$, starting $5 \mathrm{~min}$ after setting the holding potential, and at least $5 \mathrm{~min}$ after a solution change. When multiple events were superimposed, later events were counted only when they occurred after the previous current had returned to $<20 \%$ of peak value. These frequency measurements were used as a relative index of the amount of synaptic activity within and outside the scotoma. Miniature synaptic currents that would allow more accurate estimates of synaptic input number were impractical to record because of exceptionally low frequencies of these events within the scotoma when TTX was applied. Instead, measures of spontaneous NMDAR, AMPAR, and $\mathrm{GABA}_{\mathrm{A}} \mathrm{R}$ current rise times, decay times, and amplitudes were determined using the average from each set of receptor-mediated spontaneous events observed during the 3 min window. Averages were generally derived from at least 30 single events for sAMPAR and $\mathrm{SGABA}_{\mathrm{A}} \mathrm{R}$ currents and eight events for sNMDAR currents. sNMDAR rise times were calculated as time from $10-$ $90 \%$ of the total amplitude; decay times were calculated using the single exponential tau estimator as follows: time from peak to 0.37 peak amplitude.

\section{Results}

\section{NMDAR blockade enhances axon sprouting}

Small lesions of the superior/temporal retina were made at P6, and pharmacological blockade of the NMDAR with the competitive antagonist AP-5 was begun at the same time by insertion of the slow-release polymer Elvax over the sSC. Control littermates received the lesion and Elvax containing the inactive isomer L-AP-5. The complete ganglion cell projections of both eyes were differentially labeled with intravitreal injections of CTB conju- 
gated to different color fluorophores. Animals survived for $8 \mathrm{~d}$ after the lesion. Detailed characterization of these procedures has been published previously (Colonnese and Constantine-Paton, 2001). In brief, the retinal lesions result in a deafferented region, the scotoma, which is invariably located in the rostrolateral pole of the contralateral sSC. Axons from the retinal ganglion cells of the ipsilateral eye sprout into this deafferented region (Fig. $1 A$ ). The increased density of these ipsi axons within the scotoma, compared with their density immediately outside the scotoma, is used as a measure of sprouting.

As previously observed when NMDAR blockade was initiated on the day of birth, the present NMDAR blockade, initiated at the time of lesion, increased the sprouting response of ipsi axons after $\mathrm{P} 6$ lesion (Colonnese and Constantine-Paton, 2001). Antagonist-treated animals differed from control-treated littermates only in the degree, not pattern, of ipsi axon sprouting inside the lesion. Both groups showed lowdensity, ipsi projections to the nondeafferented rostral portion of the sSC characteristic of the normal ipsi projection (Table 1). In antagonist-treated, control, and untreated animals, the density of the ipsi projection diminished caudally and was not observable more than half-way along the rostrocaudal axis of the sSC, except for a small patch at the absolute caudal edge that was present in all groups. Both antagonist-treated and control animals had normal ipsi projections in the SO that included refined patches of arbor characteristic of a mature ipsilateral retinal projection (Huerta and Harting, 1984). Both antagonist-treated and control groups had an increased density of ipsi axons inside the scotoma, indicative of reactive sprouting in response to the lesion. However, antagonist-treated animals had a higher density of ipsi axons throughout the scotoma (Fig. $1 B$ ).

The sprouting response of the ipsi axons was analyzed on sections from the rostral third of the sSC. As we established previously, by consistently measuring in the same region of the lesion and sSC across all animals and discarding tissue with very small or large lesions (see Materials and Methods), we could eliminate any detectable influence of lesion size on the measured sprouting response (Colonnese and Constantine-Paton, 2001). For the current experiments, the $r^{2}$ between lesion size and sprouting was $<0.2$. Scotoma size was not affected by the drug treatments (Table 1). The sprouting index, or axon density within the deafferented region attributable to the induced sprouting, and not just the normal projection, was determined by subtracting the density of ipsi axons within the scotoma from the density of ipsi axons outside the scotoma in the same section (Fig. $1 \mathrm{~A}$, regions 2 and 1). Antagonist-treated pups had sprouting indices 2.6-fold greater than control littermates (Fig. 1C, Table 1).

\section{Early lesions result in decreased glutamatergic function} within the scotoma

Whole-cell voltage-clamp recordings of neurons were acquired from sSC slices from P10-P13 animals surviving a P6 lesion.
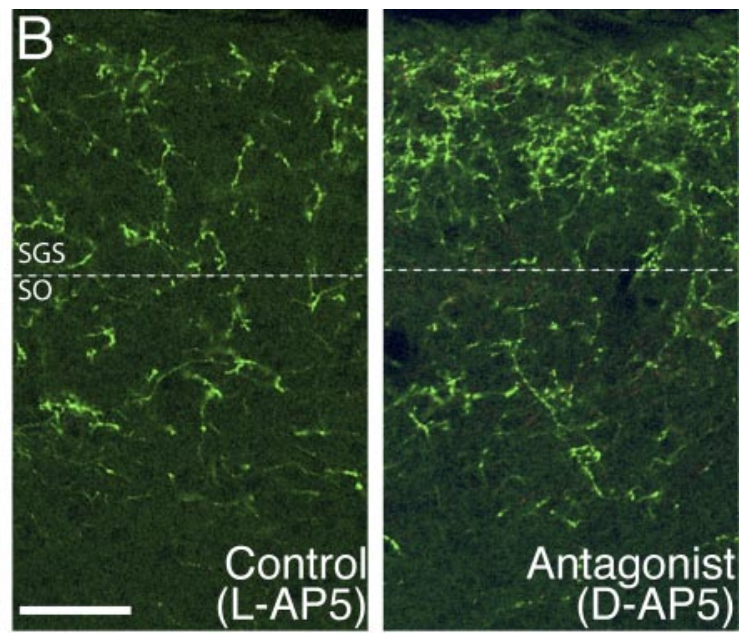

Figure 1. NMDA receptor activity suppresses retinal axon elaboration. $\boldsymbol{A}$, Ipsi axons are induced to sprout into a deafferented (T) The ipsi axons were labeled with the green CTB-Alexa 488. The scotoma can be seen in the rostrolateral portion of the sSC, where 作 ing is igure is normalized for each litter to the average amount of sprouting of the control animals (see aterials and Methods). Antagonist treatment increases sprouting compared with control littermates treated with the inactive

Comparisons of sNMDAR, sAMPAR, and sGABA $\mathrm{A}_{\mathrm{R}}$ current frequency and amplitude from neurons inside and outside the scotoma were accomplished by using the CTB label from the lesioned eye to identify the lesion site in the living slices. The spontaneous NMDAR, AMPAR, and GABA $\mathrm{R}$ currents of neurons located outside the scotoma were identical to age-matched control animals that had not received any retinal lesions (data not shown). Thus, there was no general effect of the retinal lesion on the sSC. NMDAR currents were recorded at a holding potential of $-70 \mathrm{mV}$ in $0 \mathrm{mM}$ magnesium in the presence of $6 \mu \mathrm{M} 6,7-$ dinitroquinoxaline-2,3-dione (DNQX) to block AMPA/kainate receptors and $10 \mu \mathrm{M}$ bicuculline methiodide $(\mathrm{BMI}), \mathrm{GABA}_{\mathrm{A}}$ receptor antagonist. As expected, the frequency of sNMDAR currents was markedly reduced within the scotoma (Fig. $2 \mathrm{~A}$, Table 2 ), likely reflecting fewer connections within the scotoma caused by the loss of retinal afferents. NMDAR synaptic current amplitude showed a slight reduction.

In sections of similarly processed colliculi, synaptic AMPAR and $\mathrm{GABA}_{\mathrm{A}} \mathrm{R}$ currents were examined, whereas NMDAR currents were blocked by $50 \mu \mathrm{M}$ AP-5. For AMPAR currents, the neuron was held at $-40 \mathrm{mV}$, the chloride reversal potential in which $\mathrm{GABA}_{\mathrm{A}} \mathrm{R}$ currents disappeared; $\mathrm{GABA}_{\mathrm{A}} \mathrm{R}$ currents were similarly isolated by holding the neuron at $0 \mathrm{mV}$, the reversal potential for AMPAR currents. This approach allowed examination of activity in the neuropil with excitatory and inhibitory systems essentially intact. The non-NMDAR currents observed are assumed to be AMPAR mediated, because kainate receptor activity only becomes detectable in the sSC after eye opening at approximately P14 (W. Lu and M. Constantine-Paton, personal communication). Like the sNMDAR currents, the frequency of 
Table 1. Axon sprouting and synaptic density

\begin{tabular}{|c|c|c|c|c|c|c|c|c|c|c|}
\hline \multicolumn{2}{|l|}{ Group } & \multicolumn{9}{|c|}{ Axon density } \\
\hline Lesion & Treatment & Pups & Sections & $\begin{array}{l}\text { Scotoma size } \\
\text { (percentage of sSC) }\end{array}$ & Outside (\%) & $1-\beta$ & Inside (\%) & $1-\beta$ & Sprouting index & $1-\beta$ \\
\hline \multirow[t]{6}{*}{ P6 } & Control (L-AP-5) & 7 & 21 & $13 \pm 3$ & $0.66 \pm 0.16$ & \multirow{4}{*}{0.94} & $20.06 \pm 3.38$ & \multirow{4}{*}{0.99} & $1.00 \pm 0.18$ & \multirow{4}{*}{0.99} \\
\hline & & & & & & & & & & \\
\hline & D-AP-5 & 6 & 18 & $14 \pm 3$ & $0.68 \pm 0.17$ & & $50.29 \pm 6.33^{* *}$ & & $2.56 \pm 0.33^{* *}$ & \\
\hline & Control (sham) & 6 & 18 & $14 \pm 2$ & $0.65 \pm 0.25$ & & $26.66 \pm 2.70$ & & $1.00 \pm 0.15$ & \\
\hline & & & & & & \multirow[t]{2}{*}{0.64} & & \multirow[t]{2}{*}{1.00} & & 0.99 \\
\hline & NMDA & 7 & 21 & $14 \pm 4$ & $0.13 \pm 0.06^{*}$ & & $9.02 \pm 1.18^{* *}$ & & $0.35 \pm 0.08^{* *}$ & \\
\hline \multirow[t]{3}{*}{ P11 } & L-AP-5 & 8 & 23 & $10 \pm 2$ & $0.53 \pm 0.27$ & \multirow{3}{*}{0.88} & $3.53 \pm 0.59$ & \multirow{3}{*}{0.70} & $1.00 \pm 0.20$ & \\
\hline & & & & & & & & & & 0.74 \\
\hline & D-AP-5 & 8 & 24 & $10 \pm 3$ & $0.60 \pm 0.21$ & & $4.70 \pm 0.78$ & & $1.33 \pm 0.37$ & \\
\hline
\end{tabular}

Data are averages and SEM for the anatomical measurements discussed here. Control littermates are presented above their paired experimental group. Power (1- $\beta$ ) is provided for paired comparisons to aid determination of the probability of a Type II error. Differences from control reaching statistical significance are demarcated by asterisks $\left({ }^{*} p<0.05 ;{ }^{* *} p<0.01\right)$ after the experimental condition. Sprouting and synaptic density calculations are described in Materials and Methods.
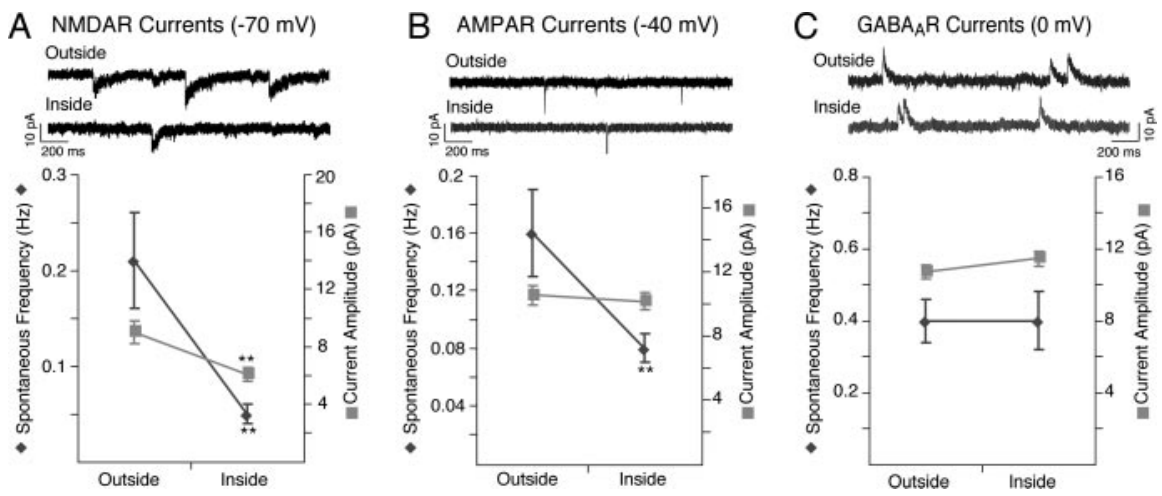

Figure 2. Synaptic currents inside and outside the scotoma. Whole-cell voltage-clamp recordings of spontaneous synaptic currents were made in slices of sSC prepared from animals killed between P10 and P13 that had received a retinal lesion at P6. The retinal projection from the lesioned eye was visualized with the anterograde tracer CTB-Alexa 546 to identify the scotoma. Neurons targeted for recording alternated between inside and outside the scotoma in individual slices. $\boldsymbol{A}$, Isolated NMDAR currents were recorded from neurons maintained at a holding potential of $-70 \mathrm{mV}$ in ACSF that contained $0 \mathrm{~mm}$ magnesium and $10 \mu \mathrm{m}$ BMI and $6 \mu \mathrm{M}$ DNQX to block GABA and AMPA/kainate channels. Representative traces from single neurons located inside and outside the scotoma from a P11 animal are shown. The average frequency (diamonds) and amplitude (squares) of spontaneous NMDAR currents for all neurons recorded is plotted. Both were significantly reduced inside the scotoma. $\boldsymbol{B}$, AMPAR currents were recorded in neurons held at the $G_{A B A}$ R reversal potential of $-40 \mathrm{mV}$. This method of isolation was chosen to eliminate inhibitory currents on the neuron but not within the remaining slice circuitry. AP-5 (50 $\mu \mathrm{m})$ was included to eliminate NMDARs; kainate receptor currents are not present at this age. The average frequency (diamonds) and amplitude (squares) of the spontaneous AMPAR currents for all neurons recorded is plotted. Spontaneous frequency was significantly reduced for neurons located in the scotoma. $\boldsymbol{C}$, In the same neurons used to record AMPARs, GABA $A_{A}$ currents were recorded after the holding potential was shifted to the AMPAR reversal potential of $0 \mathrm{mV}$. Neither the amplitude nor the frequency of spontaneous $G A B A_{A} R$ currents differs between deafferented and normal sSC.

sAMPAR currents was also reduced within the scotoma (Fig. $2 B$, Table 2). AMPAR current amplitudes and both the amplitude and frequency of $\mathrm{SGABA}_{\mathrm{A}} \mathrm{R}$ currents were the same inside and outside the scotoma (Fig. $2 C$, Table 2).

Together, the recordings indicate that after a P6 lesion, the inhibitory circuitry is intact within the scotoma. The reduction in sAMPAR and sNMDAR synaptic current frequency suggests that even by P13, $7 \mathrm{~d}$ after the lesion, the remaining glutamatergic circuitry does not compensate for the loss of the contralateral retinal input. Our anatomical experiments were performed on animals killed at P14, and thus, these early lesions reduced glutamatergic innervation of the scotoma throughout the survival period.

\section{Analyses of synaptic density along sprouting ipsilateral retinal ganglion axons}

The density of synapses on sprouting ipsi axons was measured using accumulations of the synaptic vesicle protein synaptophy- sin as a marker of the presynaptic specialization (Wiedenmann and Franke, 1985). To confirm that results were not antigen specific, a subset of experiments used the synaptic vesicle-docking protein synapsin-1 (De Camilli et al., 1983) with identical results. These light-microscope level analyses of synaptic density have many potential pitfalls. Consequently, we have applied a number of control analyses to assure that our data accurately reflect differences between treatment groups even though the absolute levels of these parameters may not be accurate. The synaptophysin and synapsin-1 reactivity was synapse-like, punctate and easily separable from background (Fig. 3A). Partial overlap of an ipsi axon and a synaptophysin puncta was extremely rare, indicating that accidental intersection of synaptophysin puncta and a terminal branch from a separate axon was not a contaminant of our data. Presumptive synapses were defined as regions of synaptic stain forming puncta larger than a minimum size (see Materials and Methods) that were completely surrounded by fluorescently tagged CTB-labeled ipsi axons. The size of synaptophysin puncta that overlapped ipsi axons ranged between $0.16 \mu \mathrm{m}^{2}$, the minimum size accepted, and $1.2 \mu \mathrm{m}^{2}$, the largest size detected, with an average size of $0.32 \pm 0.19 \mu \mathrm{m}^{2}$. Overlapped synapsin-1 puncta were between 0.10 and $0.53 \mu \mathrm{m}^{2}$, with an average size of $0.25 \pm 0.08 \mu \mathrm{m}^{2}$. Overlapped puncta above the minimum size were identified with image analysis software, but each was subsequently examined by eye to ensure that the synaptic stain was completely surrounded by the retinal axon before inclusion as synapses. The number of synapses in the sampled volume was counted using an optical dissector on the stack of optical sections. A second measure of synaptic density with no minimal size criterion, the total density of synaptophysin, or synapsin-labeled pixels within the ipsi axons, was also determined in each experiment.

To assure that our methods had sufficient resolution to reliably exclude false overlap, we compared the synaptophysin reactivity with GAD 65/67 reactivity. The former identifies all synaptic release sites, whereas the latter identifies only GABAergic synapses and should never overlap with the glutamate-releasing retinal termi- 
Table 1. (Continued)

\begin{tabular}{|c|c|c|c|c|c|c|c|c|c|c|c|}
\hline \multicolumn{6}{|c|}{ Synaptophysin staining } & \multicolumn{6}{|c|}{ Synapsin-1 staining } \\
\hline Pups & Volumes & $\begin{array}{l}\text { Synapses } \\
\left(\times 10^{-3}\right) / \mu \mathrm{m}^{3} \text { axon }\end{array}$ & $1-\beta$ & $\begin{array}{l}\text { Stain pixels } \\
\left(\times 10^{-3}\right) / \text { axon pixels }\end{array}$ & $1-\beta$ & Pups & Volumes & $\begin{array}{l}\text { Synapses } \\
\left(\times 10^{-3}\right) / \mu \mathrm{m}^{3} \text { axon }\end{array}$ & $1-\beta$ & $\begin{array}{l}\text { Stain pixels } \\
\left(\times 10^{-3}\right) / \text { axon pixels }\end{array}$ & $1-\beta$ \\
\hline 14 & 46 & $23.36 \pm 3.49$ & & $11.89 \pm 1.73$ & & 7 & 26 & $17.27 \pm 7.25$ & & $7.26 \pm 3.42$ & \\
\hline & & & 1.00 & & 0.97 & & & $12470+1$ & 1.00 & $2631+863^{*}$ & 0.66 \\
\hline $\begin{array}{l}11 \\
6\end{array}$ & $\begin{array}{l}40 \\
24\end{array}$ & $\begin{array}{l}79.64 \pm 7.30^{* *} \\
21.61+3.33\end{array}$ & & $27.93 \pm 4.17^{* *}$ & & 6 & 20 & $134.79 \pm 11.88^{*}$ & & $26.34 \pm 8.63^{*}$ & \\
\hline & & & 0.66 & & 0.87 & & & & & & \\
\hline 7 & 24 & $12.92 \pm 2.59^{*}$ & & $11.09 \pm 1.18^{* *}$ & & & & & & & \\
\hline 8 & 22 & $6.76 \pm 2.65$ & & $4.69 \pm 1.18$ & & & & & & & \\
\hline & & & 0.60 & & 0.83 & & & & & & \\
\hline 8 & 23 & $6.23 \pm 1.90$ & & $5.80 \pm 2.84$ & & & & & & & \\
\hline
\end{tabular}

nals. This examination was performed on the sprouted terminals after a P11 lesion, because by P19, when they are killed, GAD staining is well developed and easily discernable (Aamodt et al., 2000). From each of two animals studied for this control, six sections each were processed for synaptophysin or GAD 65/67 antibody staining (Fig. $3 A)$. Two $4.2 \times 10^{4} \mu \mathrm{m}^{3}$ volumes from each section $(n=12)$ were used to determine the number of overlapped synaptic puncta and pixels associated with retinal terminals for each antigen. The amount of overlap that would be expected by chance was estimated by determining the overlap values after the retinal terminal images were rotated $90^{\circ}$. The degree to which the label was greater or lower than chance was calculated by subtracting the rotated values from those determined in the nonrotated position. This "difference" value was normalized using the sum of the rotated and nonrotated values as the denominator. Positive values indicate a synaptic label that is more associated with retinal terminals than would be expected by chance; the label not associated with the axons will be negative (Silver and Stryker, 2000).

Image pixels containing synaptophysin were more likely to overlap with retinal terminals than chance. The correlation coefficient was $0.45 \pm 0.09$ (Fig. $3 B$ ). Pixels containing GAD 65/67 antigen were anticorrelated, with a correlation coefficient of $-0.21 \pm 0.18(p<0.01$ for difference between synaptophysin and GAD pixel overlap). The overlap values, when compared using the size-limited measure of puncta overlapping the ipsi axon label, showed even greater differences. Overlapped synaptophysin puncta had a correlation coefficient of $0.76 \pm 0.12$, whereas the GAD puncta coefficient was $-0.88 \pm 0.13(p<$ $0.01)$. GABAergic synapses are frequently adjacent to retinal terminals in the sSC (Lund, 1969; Mize, 1988), yet we still observed only a single overlapped GAD puncta in the nonrotated condition, indicating that our imaging is of sufficient resolution to almost completely eliminate false positives at the level of synaptic puncta.
If the overlapped synaptophysin puncta truly represent the location of synapses, they should be associated with postsynaptic specializations. To examine this, we double labeled two sections each with the synaptophysin antibody and with an antibody to one of two AMPA receptor subunits, GluR1 or GluR2 (Fig. $3 C, D)$, which should be present at mature synapses. Of all 24 synaptophysin puncta observed to be overlapped with ipsi axons, $87.5 \%$ also had a GluR1 puncta within $1 \mu \mathrm{m}$. For the GluR2 puncta, this percentage was $93.3 \%$ of the 30 overlapped synaptophysin puncta found in the samples. Many of the synaptophysin puncta not overlapping with ipsi axons did not have an associated AMPA receptor puncta within $1-2 \mu \mathrm{m}$. This may be because many local circuit sSC synapses are GABAergic.

These control observations provide strong evidence that puncta formed by the overlap of synaptophysin-immunostained and -labeled retinal axons represent synapses. These confocal data are not seriously contaminated by false overlap resulting from inadequate resolution, image-processing artifacts, or nonsynaptic accumulations of vesicles within the retinal axons.

\section{NMDAR blockade increases synaptic density after early lesions}

A total of 14 control pups and 11 NMDAR-blocked pups from four litters were used to study the synaptic density along ipsilateral retinal axons sprouting into a scotoma produced by a P6 contralateral retinal lesion. At the time of the lesion, half of the pups from each litter received an Elvax implant containing the NMDAR antagonist D-AP-5, whereas the remainder received control Elvax implants containing the inactive isomer L-AP-5. AP-5 treatment did not significantly alter the pattern or intensity of the synaptophysin stain. Neither the number of overlapped pixels nor the number of puncta were correlated with the total density of synaptic stain in the same volumes $\left(r^{2}<0.0008\right)$. However, both overlap measures were highly correlated with the

Table 2. Synaptic current properties

\begin{tabular}{|c|c|c|c|c|c|c|c|}
\hline \multirow[b]{2}{*}{ Current } & & \multicolumn{3}{|c|}{ P6 lesions (P10 - P13) } & \multicolumn{3}{|c|}{ P11 lesions (P15-P17) } \\
\hline & & Outside scotoma & Inside scotoma & $1-\beta$ & Outside scotoma & Inside scotoma & $1-\beta$ \\
\hline \multirow[t]{3}{*}{ NMDAR } & Number of pups/neurons & $6 / 20$ & $6 / 25$ & & $7 / 25$ & $9 / 20$ & \\
\hline & Frequency $(\mathrm{Hz})$ & $0.21 \pm 0.05$ & $0.05 \pm 0.01^{* *}$ & 0.93 & $0.27 \pm 0.06$ & $0.15 \pm 0.05$ & 0.64 \\
\hline & Amplitude (pA) & $9.03 \pm 0.81$ & $6.11 \pm 0.48^{* *}$ & 0.92 & $6.49 \pm 0.58$ & $5.54 \pm 0.30$ & 0.72 \\
\hline \multirow[t]{3}{*}{ AMPAR } & Number of pups/neurons & $7 / 46$ & $9 / 46$ & & & & \\
\hline & Frequency $(\mathrm{Hz})$ & $0.16 \pm 0.03$ & $0.08 \pm 0.01^{* *}$ & 0.82 & & & \\
\hline & Amplitude (pA) & $10.52 \pm 0.60$ & $10.14 \pm 0.52$ & 0.80 & & & \\
\hline \multirow[t]{3}{*}{$\mathrm{GABA}_{\mathrm{A}} \mathrm{R}$} & Number of pups/neurons & $7 / 46$ & 9/46 & & & & \\
\hline & Frequency $(\mathrm{Hz})$ & $0.40 \pm 0.06$ & $0.40 \pm 0.08$ & 1.00 & & & \\
\hline & Amplitude (pA) & $10.70 \pm 0.37$ & $11.45 \pm 0.42$ & 0.67 & & & \\
\hline
\end{tabular}



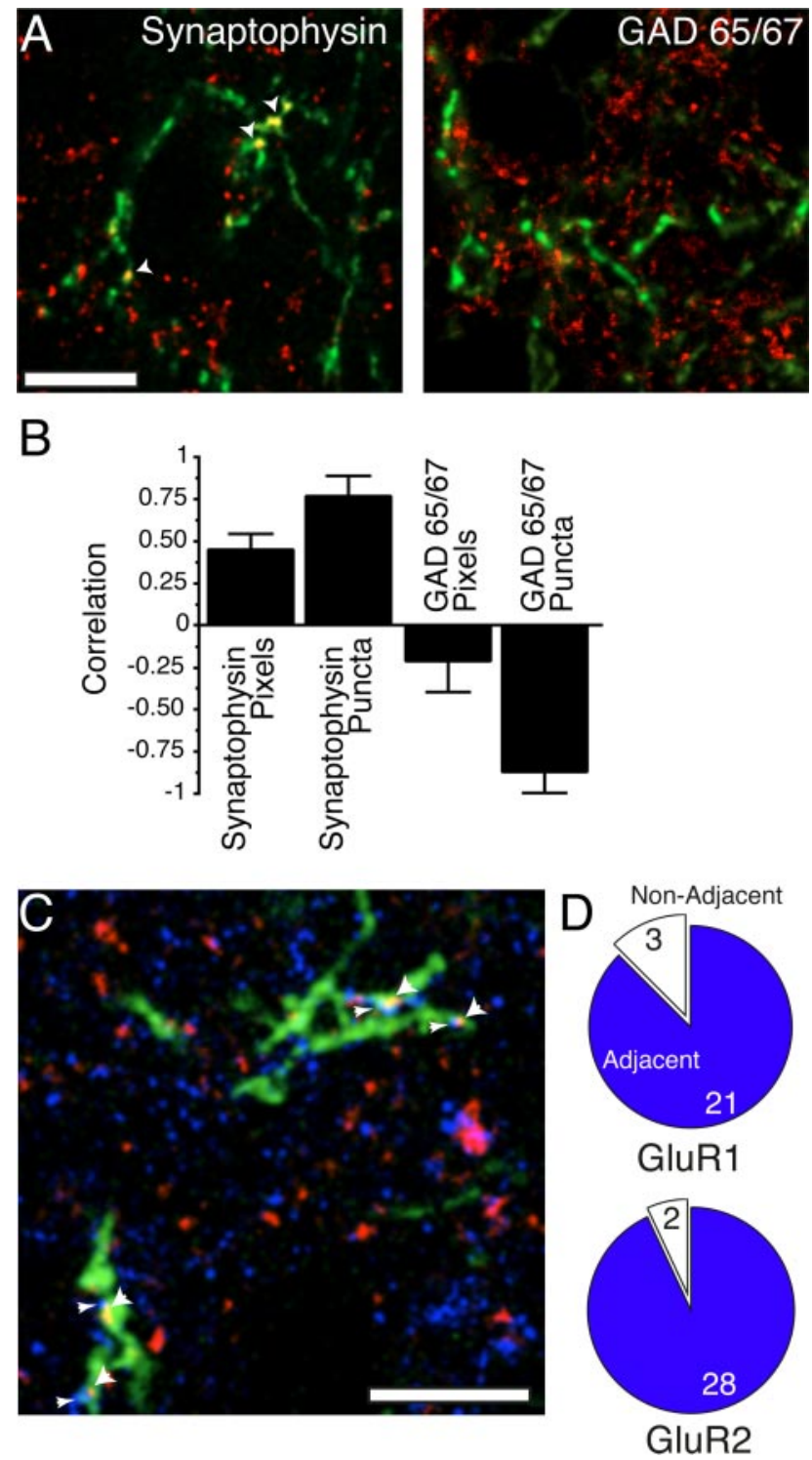

Figure 3. Immunohistochemistry for synapse-associated proteins can be used to count retinal ganglion cell axon synapses. $\boldsymbol{A}$, Confocal micrographs of sSC sections from an animal in which the ipsilateral retinal ganglion cell axons were labeled with the anterograde tracer CTB-Alexa 488 (in green). Immunohistochemistry for the synapse-associated proteins synaptophysin or GAD 65/67 was used to identify presynaptic release sites. GAD staining served as a control for the resolution of our technique, because it should never be localized to retinal axons. Antibodies are visualized with Alexa 546-conjugated secondary antibodies (red). In the left panel, synaptophysin-positive puncta are easily identifiable and separable from the background. These puncta overlap (yellow; marked by white arrowheads) with retinal axons at swellings of the axon that are indicative of a bouton. The micrograph on the right is of a section stained for the presynaptic marker ofGABAergic synapses, GAD65/67. It does not show any overlap with the retinal axons. $\boldsymbol{B}$, Correlation coefficients of overlap between ipsi axons and the synapse-associated proteins. A positive correlation indicates that the overlap of axon and antigen is greater than would be expected by chance (see Materials and Methods). This correlation coefficient was determined for the number of overlapped pixels as well as for the number of pixel accumulations that exceeded $0.16 \mu \mathrm{m}^{2}$ (puncta), our minimal criterion for a synapse. Synaptophysin antigens show more overlap, and GAD 65/67 localization shows less overlap, than would be expected by chance, especially when the minimal size criterion is imposed. Data were acquired from 12 sections from two animals for each antigen. $C$, Overlapped synaptophysin puncta are adjacent to postsynaptic markers. A confocal micrograph of tissue triple labeled for the ipsilateral RGC axons and synaptophysin (red; overlap is yellow) and also for the postsynaptic glutamate receptor GluR1 (blue) is shown. Presumptive synapses are marked with a large arrowhead. All identified presumptive synapses are adjacent to at least one GluR1 puncta, marked with a small arrowhead. D, Proportion of overlapped synaptophysin puncta from four sections with a GluR1 (top) or GluR2 (bottom) puncta within $1 \mu \mathrm{m}$. Only a small number of such overlapped synaptophysin puncta were not apposed to glutamate receptor accumulations. Scale bars, $10 \mu \mathrm{m}$. density of ipsi axon arbor $\left(r^{2}>0.6\right)$ in the volumes for both AP-5 and control-treated animals.

Pups in which the NMDAR had been blocked during the course of the sprouting were analyzed for ipsi axon synaptic density within the scotoma (Fig. $4 A-C$ ). To estimate the synaptic density along ipsi axon arbors, the number of overlapped puncta counted in the sampled volumes of tissue were divided by the total volume of ipsi axons in the sample. This parameter reveals whether the increase in synaptic puncta observed in a sample is the result of a real increase in the frequency of synaptic contacts per unit of axon volume. Compared with littermate controls, synaptic density was increased by more than threefold (Fig. 4D, Table 1) by NMDAR blockade after the early lesions.

The counting of synaptic puncta is a stringent measurement designed to give some estimate of the number of actual synapses along the ipsi axons, but it can also introduce size bias into the data. A less stringent measure, the pixels that contained both immunolabel and ipsi axon label were counted, and this number was normalized to the amount of axon in the sampled volume. Pups from the NMDAR-blocked group had a higher density of overlapped synaptophysin pixels than littermate controls, similar to the results seen for the puncta (Fig. $4 E$ ).

To confirm that the results obtained using synaptophysin reactivity as a marker for synaptic release sites was not dependent on the specific antigen, the skipped sections from two of the litters described above were processed with the synapsin-1 antibody. The results were identical: densities of both overlapped puncta and pixels were increased after NMDAR blockade (Table 1). Thus, NMDAR blockade during ipsi axon sprouting into the sSC scotoma after a P6 retinal lesion resulted in a higher synaptic density and absolute density of synaptophysin and synapsin-1 stain per unit volume of sprouted axon.

\section{Synaptic depression reduces sprouting and synaptic density}

The results of the antagonist treatment experiments above suggest that NMDAR activity is reducing the number of synapses along growing retinal axon terminals. We wanted to directly test the hypothesis that these structural changes could result from a predominance of functional NMDAR-dependent, synaptic depression at the newly formed synapses. Shi et al. (2001) showed that chronic exposure of the sSC to low levels of the agonist NMDA caused a pronounced decrease in the spontaneous frequency of sSC glutamatergic currents and a specific decrease in the frequency of miniature AMPAR currents (Shi et al., 2001). Consequently, we used the chronic NMDA treatment to determine whether this functional synaptic depression reduced ipsi axon sprouting and synapse formation. Like the antagonist treatment, agonist treatment caused changes only in the amount, and not the patterning, of the sprouting ipsilateral projection. A lowdensity projection persisted in the SGS and SZ in the rostral portion of the sSC, and higher density clumps of arbor were present in the SO. Within the scotoma caused by the P6 lesion, the SGS and SZ still showed evidence of reactive ipsi axon sprouting in NMDA-treated animals.

Quantitative data on sprouting and synapse density was obtained from two litters treated as described for the antagonist experiments, except that the Elvax contained NMDA or vehicle (sham/control). In the rostral portion of the sSC, NMDA treatment reduced the density of the ipsilateral projection outside the scotoma (Fig. $1 A-1$ ) by $80 \%$ (Table 1 ). Axon density was also examined in the SO, but variability of ipsi axon density in this layer was so great that it was not possible to make a statistically valid conclusion. 
The amount of ipsi axon sprouting into the scotoma was also reduced by NMDA treatment (Fig. $5 A, B$ ), by $65 \%$ in NMDAtreated pups compared with sham/control littermates (Table 1). The number of synapses identified in each ROI by synaptophysin staining was also reduced by NMDA treatment (Fig. 5C,D). After normalization for axon volume, a $40 \%$ reduction of synaptic density was observed (Fig. $5 E$, Table 1 ). The absolute volume of synaptophysin staining was reduced to a lesser (31\%), although significant, degree. These anatomical observations, in conjunction with the earlier electrophysiological examination after the same treatment (Shi et al., 2001), support the conclusion that functional synaptic depression is tightly associated with, if not the cause of, the structural loss of synapses and decreased sprouting of ipsi axons.

\section{Late lesions are not affected by antagonist treatment}

We previously found that when retinal lesions are made at P11 instead of P6, NMDAR blockade from birth only increases sprouting of the ipsilateral projection if the occipital cortex is simultaneously removed (Colonnese and Constantine-Paton, 2001). Increased competition as a result of the invasion of a dense cortical projection is therefore a likely cause of the loss of NMDAR antagonist effect on ipsi axon sprouting after P11 lesions. The normal cortical projection to the sSC is much denser than the ipsi projection and therefore may more effectively occupy synaptic sites made available by contralateral retinal axon removal. The corticocollicular projection is, like the retinal projections, glutamatergic (Jeon et al., 1997). Consequently, if there is increased arborization of cortical axons during the survival time after late lesions, there should be a less pronounced reduction of glutamate currents within the scotoma produced by the late lesion. We tested this prediction with whole-cell recordings of spontaneous NMDAR currents, similar to those described above, within and outside the sSC scotoma of pups that received a retinal lesion at P11. The animals were killed between P15 and P17. As predicted, the frequency of spontaneous synaptic currents did not differ between neurons located inside or outside the scotoma (Fig. 6A, Table 2). In addition, the spontaneous NMDAR current frequency inside the scotoma of older animals surviving a P11 lesion was not significantly different from that found outside the scotoma of the younger animals that sustained the earlier lesion [power of the test $(1-\beta), 0.736$ ]. This suggests that, by $4 \mathrm{~d}$ after a late lesion, the level of glutamatergic activity inside the scotoma had returned to a level normally present in the sSC at the time of the lesion.

The increased innervation from the cortex competitively reduced the sprouting of the ipsi axon projection, as demonstrated
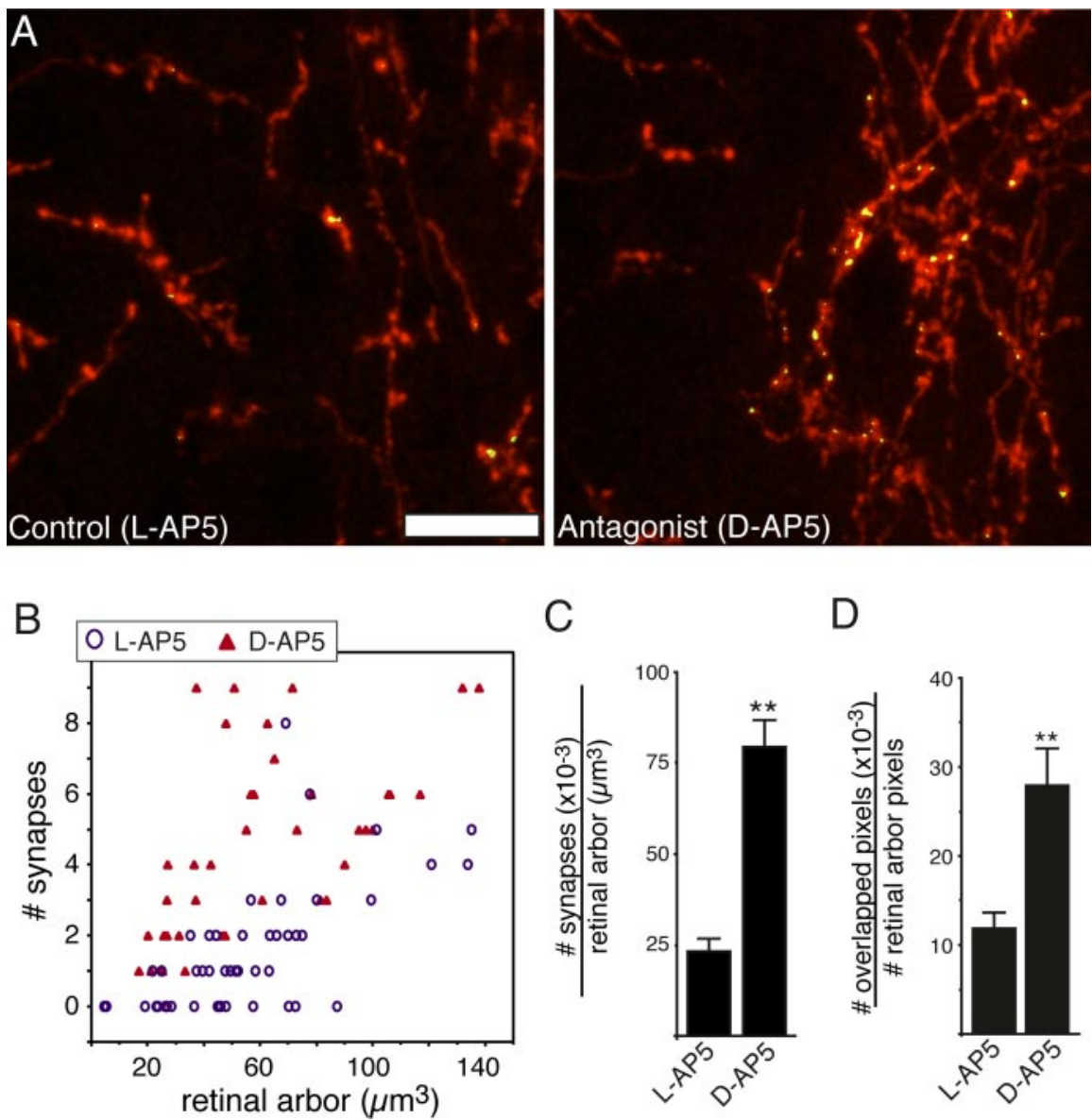

C
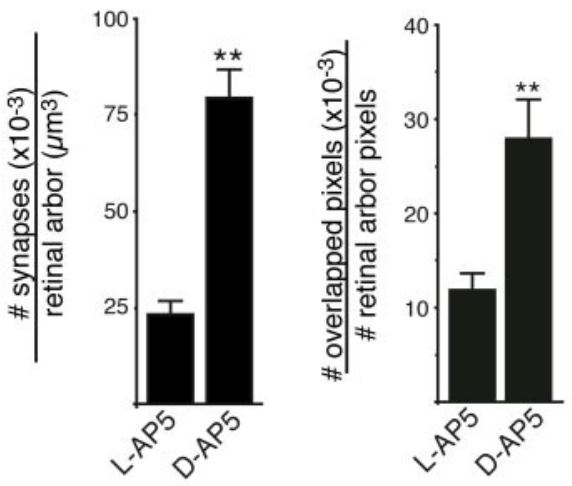

Figure 4. NMDAR blockade increases synaptic density. $\boldsymbol{A}$, Two-dimensional, brightest-point projections of a $4 \mu \mathrm{m}$ tissue volume showing the sprouting ipsilateral RGC axons (red) within the volume as well as the places where these axons overlapped with the synaptophysin antibody (yellow). The volumes shown are from inside the scotoma of P14 pups that received a retinal z-plane. On the right is an SSC treated with the antagonist D-AP-5, which has a greater density of axons within the scotoma as well s more synaptic puncta than the SSC from L-AP-5-treated control littermates. $\boldsymbol{B}$, Scatter plot of the number of synapses identified of NMDAR blockade is not dependent on a minimal size criterion used to identify synapses. When the absolute density of overlap between the synaptophysin antibody and the retinal axons, without regard to the size of the overlapped puncta, is plotted, NMDAR blockade still significantly increases this overlap. Scale bar, $10 \mu \mathrm{m}$. ${ }^{* *} p<0.01$

in our previous work (Colonnese and Constantine-Paton, 2001). Here, we asked whether the decrease in sprouted ipsi axon volume was also associated with a decrease in ipsi axon synapse density. Thus, we repeated the NMDAR blockade experiment described previously, but beginning both the NMDAR blockade and the lesion at P11.

In the late lesioned animals, NMDAR blockade had no effect on the amount of sprouting into the scotoma (Fig. 6B, $C$; Table 1). Furthermore, no quantitative or qualitative effects of the late blockade could be discerned in the arbor patterns of the ipsi projection outside the scotoma. These observations support our previous conclusions that competing axon density, not NMDAR currents, is the factor suppressing sprouting as the animal ages and neuropil innervation density increases. In this context, it is relevant that the present studies used the time of the lesion as the time of onset of the NMDAR blockade. The previous work started the NMDAR blockade at birth (Colonnese and Constantine-Paton, 2001). Consequently, the present duplica- 

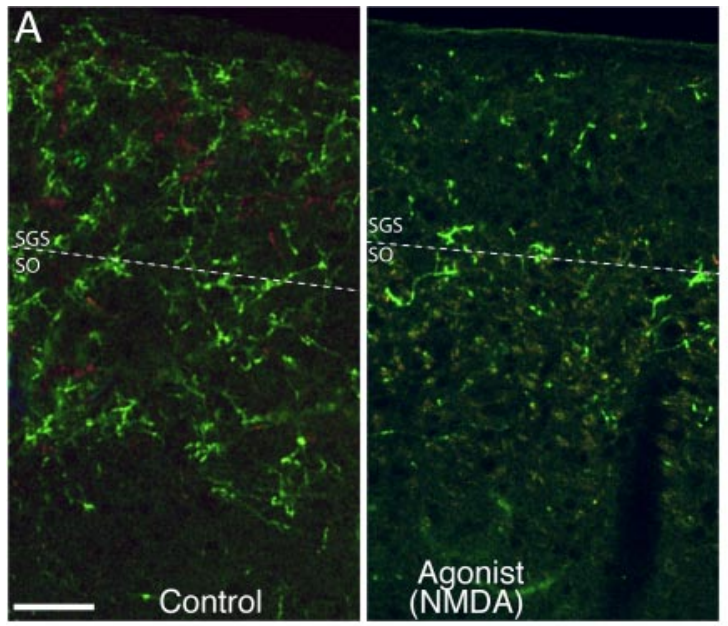

B

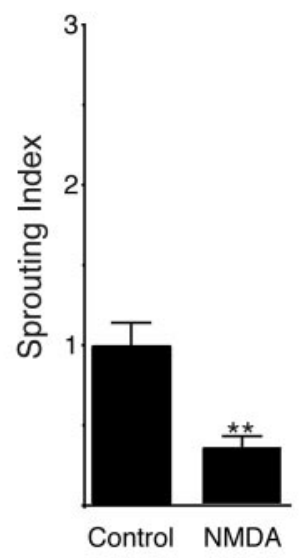

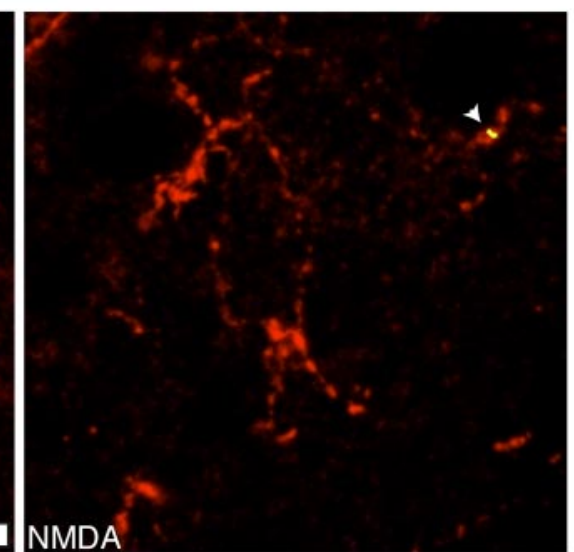

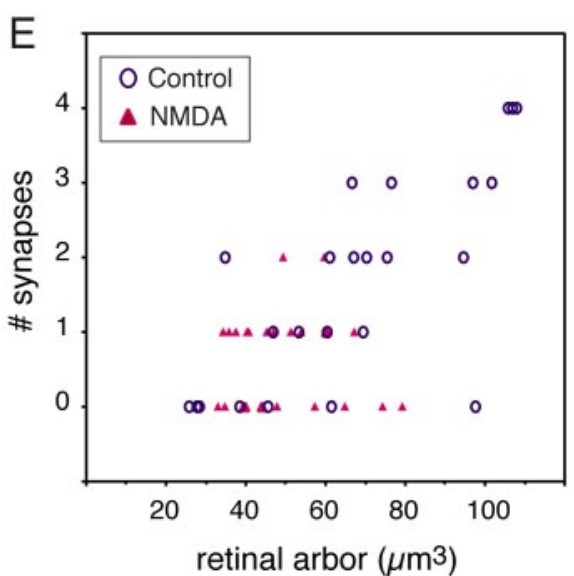

D

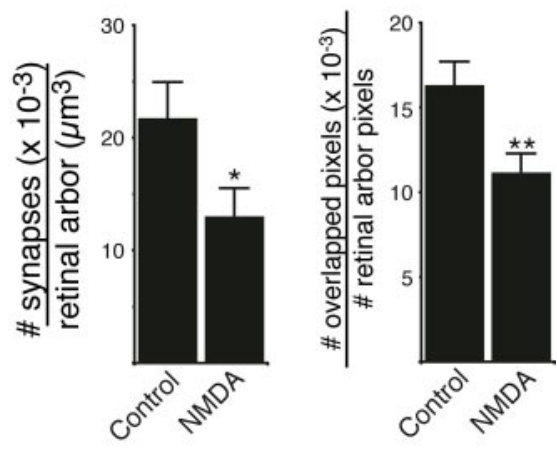

Figure 5. The effects of NMDAR agonist treatment are opposite those of the antagonist treatment. $\boldsymbol{A}$, Agonist treatment reduces the ipsi axon sprouting after a P6 lesion. Shown are micrographs of coronal sections from a sham Elvax control pup and an NMDA-treated pup showing ipsi axons (green) within the scotoma. The pial surface is at the top. The approximate border between the SGS/SZ and SO is demarcated by the dotted line. B, Quantification of sprouting after a P6 lesion in the presence of NMDA. Pups that received the NMDA treatment demonstrated significantly less sprouting in the scotoma than their littermate controls. $\boldsymbol{C}$, Ipsi axon synapses are reduced by NMDA treatment. Brightest-point projections of a $4 \mu \mathrm{m}$ depth of sSC neuropil showing the sprouting ipsilateral RGC axons (green) within the volume as well as the places where these axons overlapped with the synaptophysin antibody (yellow). The total synaptophysin staining is not shown to exclude regions of false overlap from different locations on the z-plane. Presumptive synapses are marked by an arrowhead. There are fewer overlaps in NMDA-treated animals, as well as less axon arbor. $\boldsymbol{D}$, Scatter plot of the number of synapses identified by overlap of ipsi axon and synaptophysin puncta larger than $0.16 \mu \mathrm{m}^{2}$ plotted against the volume of retinal axon in each sampled region. This plot shows that for all axon densities, the number of synapses is fewer in the NMDA-treated group, but that absolute quantification changes in synapse density require division by axon density. $\boldsymbol{E}$, Density of ipsi axon synapses. NMDA treatment significantly reduced this synaptic density. This number is a relative, not absolute, measure of synaptic density. $\boldsymbol{F}$, The effect of NMDA treatment is not dependent on a minimal size criterion for identification of synapses. When the absolute density of overlap between the synaptophysin antibody and the retinal axons without regard to the size of the overlapped puncta is plotted, NMDA treatment still reduces the amount of synaptophysin in ipsi axons. Scale bars: $\boldsymbol{A}, 100 \mu \mathrm{m} ; \boldsymbol{C}, 10 \mu \mathrm{m}$. ${ }^{* *} p<0.01 ;{ }^{*} p<0.05$. tion of the previous sprouting findings rule out the possibility, remaining from the previous study, that the lack of an NMDAR blockade effect on animals with P11 lesions was an artifact of exhaustion of D-AP-5/Elvax implanted from birth.

The density of overlapped synaptophysin puncta along the sprouted axons (Fig. $6 D)$ and the density of overlapped pixels (Fig. 6E) were also unaltered by NMDAR blockade in sSCs with retinal lesions at P11. Therefore, like ipsi sprouting, the reduction of synaptic density on ipsi axons in the scotoma after P11 lesions probably resulted from competition for synaptic space arising from maturing corticocollicular terminals. This competitioninduced reduction is independent of functioning NMDARs.

The combined electrophysiological, axon sprouting, and synapse density findings are therefore internally consistent. They support the postulate that intense competition for synaptic space in developing neuropil, or the lack of it, is the dominant factor determining whether sprouting and synapse formation will occur or be suppressed. The findings from this and our previous study indicate that when synaptic space is limited, NMDAR activation no longer controls the net number of synapses made by a developing projection.

\section{NMDAR current kinetics after late and early lesions}

The conclusion that competition for synaptic space eliminates or occludes any effect of NMDAR blockade in older animals assumes that no parameter other than synapse density has changed between the two initiation times. However, there is a known developmental change that might be involved: NMDAR currents decrease in decay time as the sSC neuropil matures. In the sSC, the decay time of synaptic NMDAR currents shortens $\sim 50 \%$ between P10 and P11 (Shi et al., 1997), during the P6 lesion survival period but before the P11 lesions. Such reductions could render the currents unable to reduce synapse survival and ipsi axon sprouting in older animals. Consequently, we compared the decay times of sNMDAR currents on neurons located inside the scotoma, with decay times from neurons in the same slices outside the scotoma. Spontaneous NMDAR currents were isolated as described previously, and average sNMDAR currents were generated for each neuron. Rise times and decay times were measured from the averages (Fig. 7).

Neurons located inside the scotoma after an early lesion had synaptic NMDAR current decay and rise times that were sig- 
nificantly shorter than those of neurons located outside the scotoma (Fig. 7A, Table 3 ). That both rise and decay time changed in parallel suggests that the active synapses within the scotoma were closer to the recording site in the soma than most currents recorded outside the scotoma. To control for the change in proximity, the decay time for each neuron was normalized by the rise time to generate a relative estimate of decay time independent of dendritic location. The normalized sNMDAR current decay times were still significantly reduced inside compared with outside the scotoma (Fig. $7 B$ ). Pups that received a late lesion had the short sNMDAR current decay times both inside and outside the scotoma (Fig. $7 B$, Table 3 ). Thus, the absence of any difference in NMDAR decay time inside the scotoma between early and late lesions $(1-\beta, 0.60)$ offers no support for the hypothesis that such changes in receptor function play a role in the developmental loss of sensitivity to NMDAR blockade.

\section{Discussion}

The precise relationship between NMDAR current kinetics, axonal in-growth, synapse addition, elimination, and competition from other axons is not well understood. We used a previously reported quantitative assay of retinal axon sprouting within the sSC (Colonnese and Constantine-Paton, 2001) to arrive at three conclusions about these relationships: (1) the ability of retinal axons to make synapses is tightly linked to their sprouting capacity, and it appears that functional synapses are necessary for retention of axonal arbors (Fig. 8); (2) normally, NMDAR activity reduces synapse formation by sprouting ipsilateral retinal axons when the sSC is sparsely innervated; and (3) competition between the sprouting ipsi axons and other glutamatergic afferents (like corticocollicular axons) for synaptic space does not require NMDAR activity.

As described by previous studies (Lund and Lund, 1976; Frost and Schneider, 1979; Simon et al., 1994), a small lesion in a particular region of the contralateral retina will cause axons from the ipsilateral retina to sprout and form synapses within a predictably positioned deafferented zone. We used fluorescent anterograde tracers and immunohistochemistry for synaptic vesicles to identify synapses along sprouting ipsi retinal axons. Theoretically, quantitative electron microscopic (EM) analysis of synaptic release sites could be applied in this analysis. However, quantitative EM analysis is exceptionally difficult to use here, because synapses from only one projection must be studied, and a large number of axons from the projection must be sampled. Quantitative, light microscope techniques have been used previously for identification of synapse distribution and density (Pinches and Cline, 1998; Silver and Stryker, 1999, 2000). This measure provides a
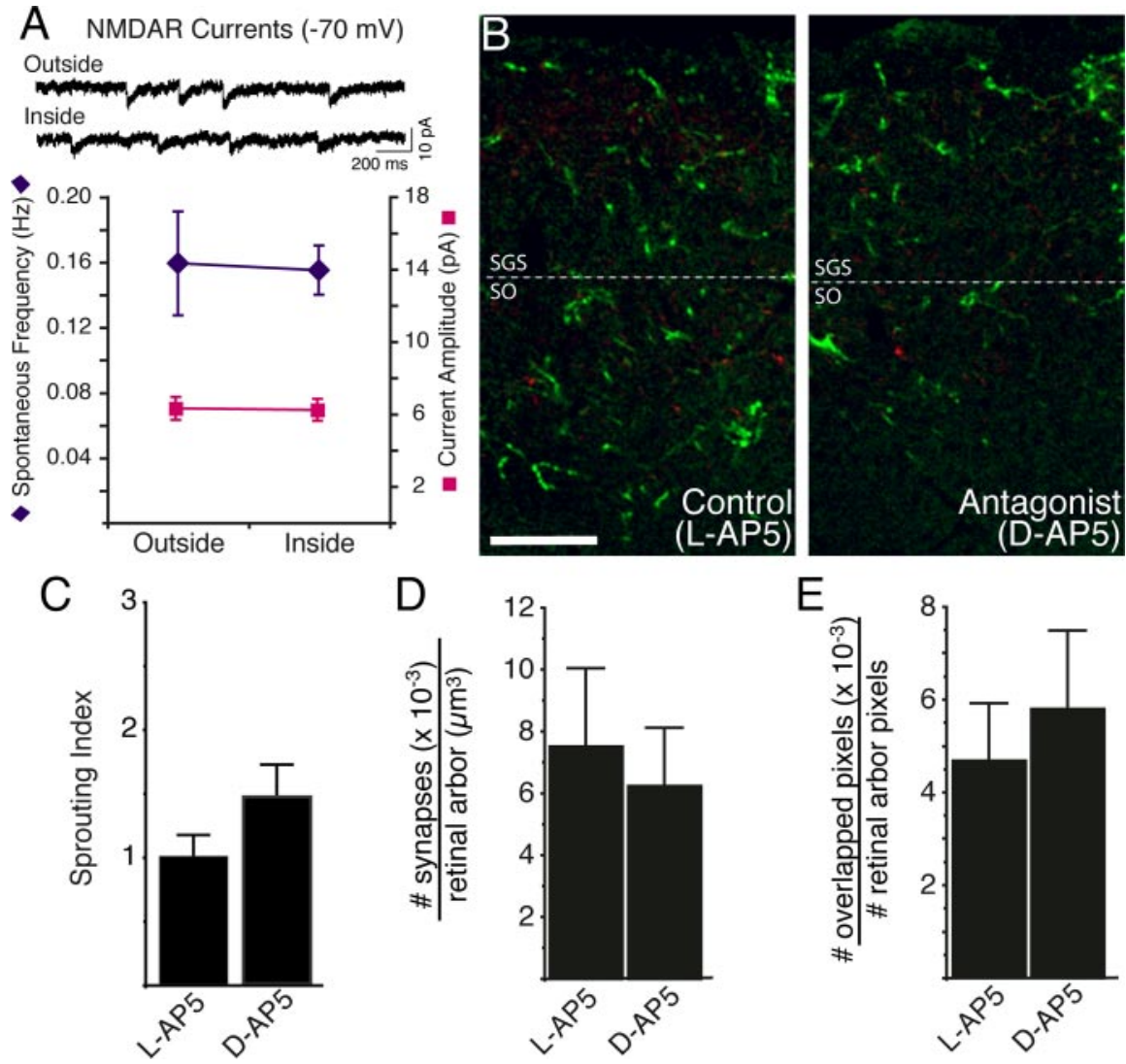

E

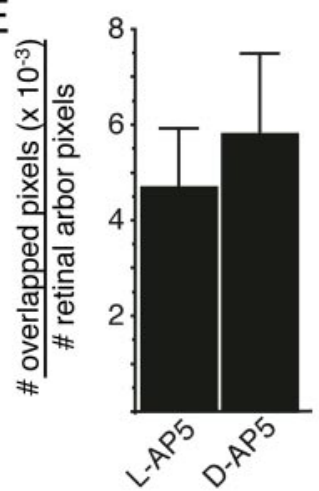

Figure 6. NMDAR blockade has no effect after a P11 lesion. $\boldsymbol{A}$, Late lesions leave much of the glutamatergic circuitry intact. Spontaneous NMDAR currents were recorded from neurons maintained at a holding potential of $-70 \mathrm{mV}$ in ACSF that contained was unchanged by NMDAR blockade compared with littermate controls. $\boldsymbol{E}$, The lack of effect of late NMDAR blockade is not dependent on the minimal size criterion used to identify puncta. The absolute amount of synaptophysin stain within ipsi terminals is also unchanged. Scale bar, $150 \mu \mathrm{m}$.

relative, although not absolute, estimate of synaptic density. Puncta of synaptophysin reactivity associate with regions of membrane recycling indicative of active synapses (van den Pol et al., 1998; Hopf et al., 2002), but the immunolabel has also been shown in vitro to label more vesicle clusters than are activated by exposure to high potassium (Korkotian and Segal, 2001). Staining for postsynaptic density proteins GluR1 and GluR2 indicate that our synaptophysin puncta are almost always adjacent to postsynaptic densities, but it is possible that a small portion of the synapses we label are not active.

We used the following six procedures to minimize technical artifacts or biases in these analyses: (1) treatment-blind analysis of the anatomical data; (2) overlap studies (Fig. 2A,B) using anti$\mathrm{GAD}$ antibodies to indicate that significant accidental overlap of nearby fluorescence is not biasing estimates of synapse density; (3) use of both the unbiased measure, "total synaptophysinlabeled pixel density," and the size limited criterion for synaptic puncta to assure that the analyses of relative synapse number 


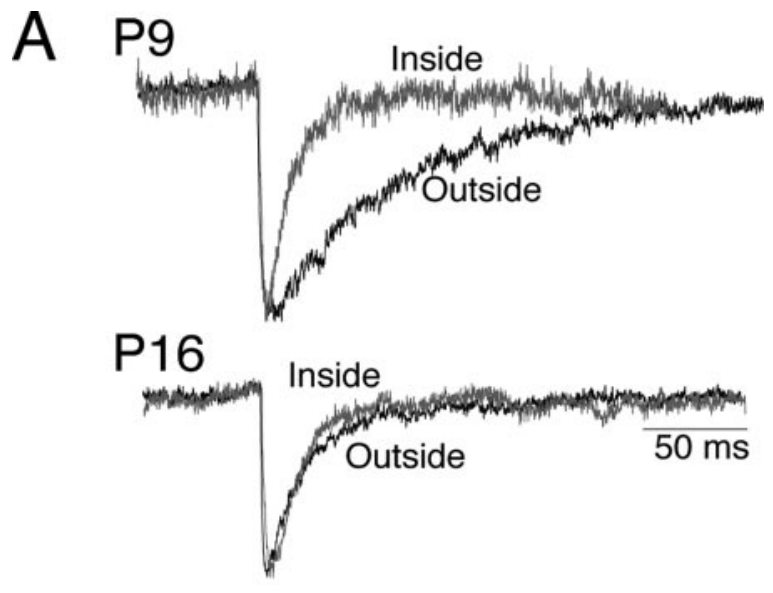

B

\section{Decay/Rise Time}

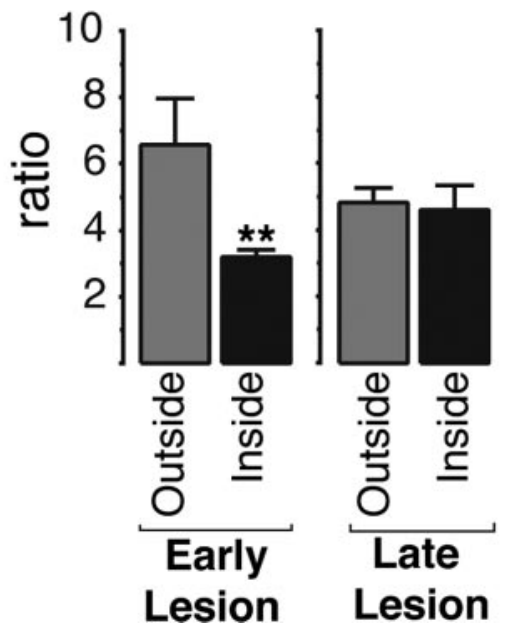

Figure 7. Kinetics of spontaneous NMDAR currents in lesioned animals. A whole-cell voltage-clamp recording in the presence of $10 \mu \mathrm{M} B M I$ and $6 \mu \mathrm{M}$ DNQX to block $\mathrm{GABA}_{\mathrm{A}}$ and AMPA/kainate channels was used to measure NMDAR currents. The location of the scotoma was determined by visualization of the contralateral retinal projection with fluorescent CTB before the selection of neurons for recording. $\boldsymbol{A}$, Average NMDAR EPSC traces are calculated from all of the spontaneous events of a single neuron. The average NMDAR current from a neuron within the scotoma of the $P 9$ pup decays faster than one from a neuron of the same pup located outside the scotoma. The neuron of a P16 animal that received a late lesion has fast-decaying currents both inside and outside the scotoma. $\boldsymbol{B}$, The remaining synapses inside the scotoma formed by an early lesion have NMDAR currents with a shorter decay time. Reported here is the ratio of the decay time to the rise time. Both average rise time and decay time were reduced on neurons located inside the scotoma after an early lesion (see Table 2 for complete data). The decrease in rise time suggests that the remaining synapses are closer to the recording site in the soma. To normalize for such a change in position, the current decay time of each neuron was divided by its rise time. Early lesions were made at $\mathrm{P} 6$, and averages include animals killed between $\mathrm{P} 9$ and P13; late lesions were made at P11 and killed between P15 and P17. Early lesions result in a shorter normalized NMDAR current decay time. Late lesions do not have an effect on current decay time, possibly because they have already shortened. ${ }^{* *} p<0.01$.

were not distorted by our judgment of expected vesicle cluster size; (4) use of antibodies against two different synaptic vesicleassociated proteins, synaptophysin and synapsin-1, to assure that our results were not biased by the particular antigen/antibody interaction used; (5) use of equal numbers of littermates as controls to minimize litter effects (Colonnese and ConstantinePaton, 2001); and (6) simultaneous processing of whole litters with the same solution set to reduce variability.
NMDAR activity reduces synapse formation on sprouting ipsilateral retina axons

The NMDAR can be a critical component of competition for synaptic space among converging axons during development (Cline et al., 1987; Hahm et al., 1991; Simon et al., 1992; Fox et al., 1996). One prevalent theory is that coordinated patterns of activity facilitate afferent stabilization by activating postsynaptic receptors (Constantine-Paton et al., 1990; Katz and Shatz, 1996). However, despite disruption of topography or lamination, retinal axons can elaborate in the absence of presynaptic action potentials (O'Leary and Cowan, 1983; Thompson and Holt, 1989; Cook et al., 1999) or postsynaptic NMDAR activity (Cline et al., 1990; Hahm et al., 1999). Glutamatergic synaptic function also develops relatively normally in the absence of NMDAR activity (Zhu and Malinow, 2002; Colonnese et al., 2003). Thus, NMDAR activity is not required for the development of synapses, even though it is important for synaptic refinement.

Our results extend these findings by showing that when an axon projection is actively invading relatively uninnervated neuropil, blockade of NMDAR activity results in an increased density of synapses along each axon. This implies that normal NMDAR function at this developmental stage either blocks synapse formation or minimizes the lifetime of constitutively established contacts. Thus, our observations are the opposite of the decrease predicted if NMDAR activity normally stabilized young synapses. It is likely that the increase in synaptic density observed presently is a direct result of lost NMDAR function, because there are no functional changes in calcium permeability, current amplitude, frequency of AMPARs, or the expression of 13 different synaptic proteins (Colonnese et al., 2003) after the blockade.

It is not surprising that the synapses of young ipsi axons are eliminated by NMDAR activation, because they are likely to be weak, sparse, and poorly correlated. Such activity is predicted to favor NMDAR-mediated depression of their synapses and their eventual elimination (Stent, 1973; Bear and Rittenhouse, 1999). The fact that low NMDAR activation produced by weak inputs promotes synapse loss, as a result of extended synaptic depression, is supported by our finding that NMDA agonist application decreases both ipsi axon sprouting and synapse density. The long-term depression at sSC glutamate synapses (Shi et al., 2001) observed with this treatment probably results because the low levels of agonist partially desensitize NMDARs, favoring a more pronounced synaptic depression (Artola et al., 1990; Sather et al., 1992; Nishiyama et al., 2000).

\section{The relative roles of competition and NMDAR function}

The present results, together with our previous study (Colonnese and Constantine-Paton, 2001), indicate that later in development, NMDAR blockade no longer increases synapses or augments sprouting of ipsi axons within a scotoma. In the period after P11 lesions, the corticocollicular axons are densely arborizing in the colliculus (Lopez-Medina et al., 1989). We have shown by cortical ablation that the presence of these axons represses ipsi axon sprouting even during NMDAR blockade (Colonnese and Constantine-Paton, 2001). In the present study, whole-cell patch-clamp recordings demonstrate that the frequency of spontaneous glutamate activity in the scotoma is reduced only after the P6 but not the P11 lesions. This also supports our suggestion that it is increased competition for synaptic space on the collicular neurons that limits, independent of NMDAR function, the ability of the ipsi axons to establish contacts in the sSC. Finally, the analyses of NMDAR current kinetics in and out of the deafferented neuropil in this study also rule out an alternative possi- 
Table 3. Synaptic NMDA receptor current kinetics

\begin{tabular}{|c|c|c|c|c|c|c|c|}
\hline \multirow[b]{2}{*}{ Current } & & \multicolumn{3}{|c|}{ P6 lesions (P9-P13) } & \multicolumn{3}{|c|}{ P11 lesions (P15-P17) } \\
\hline & & Outside scotoma & Inside scotoma & $1-\beta$ & Outside scotoma & Inside scotoma & $1-\beta$ \\
\hline \multirow[t]{4}{*}{ NMDAR } & Number of pups/neurons & $6 / 20$ & $6 / 25$ & & $7 / 25$ & $9 / 20$ & \\
\hline & Rise time (ms) & $4.19 \pm 0.34$ & $3.20 \pm 0.17^{* *}$ & 0.83 & $3.04 \pm 0.22$ & $2.94 \pm 0.24$ & 0.85 \\
\hline & Decay time (ms) & $23.09 \pm 2.08$ & $10.30 \pm 1.00^{* *}$ & 1.00 & $13.13 \pm 1.17$ & $11.69 \pm 1.30$ & 0.76 \\
\hline & Decay/rise (ratio) & $6.57 \pm 1.40$ & $3.20 \pm 0.21^{* *}$ & 0.76 & $4.69 \pm 0.43$ & $4.48 \pm 0.70$ & 0.86 \\
\hline
\end{tabular}

Data are averages and SEM of the rise and decay times of spontaneous NMDAR synaptic currents discussed here. The decay time, normalized to rise time for each neuron, is also tabulated as a control for the average synaptic difference from the scotoma. Power $(1-\beta)$ is provided for paired comparisons to aid determination of the probability of a Type Il error. Differences from control reaching statistical significance are demarcated by asterisks $\left({ }^{* *} p<0.01\right)$ after the experimental condition.

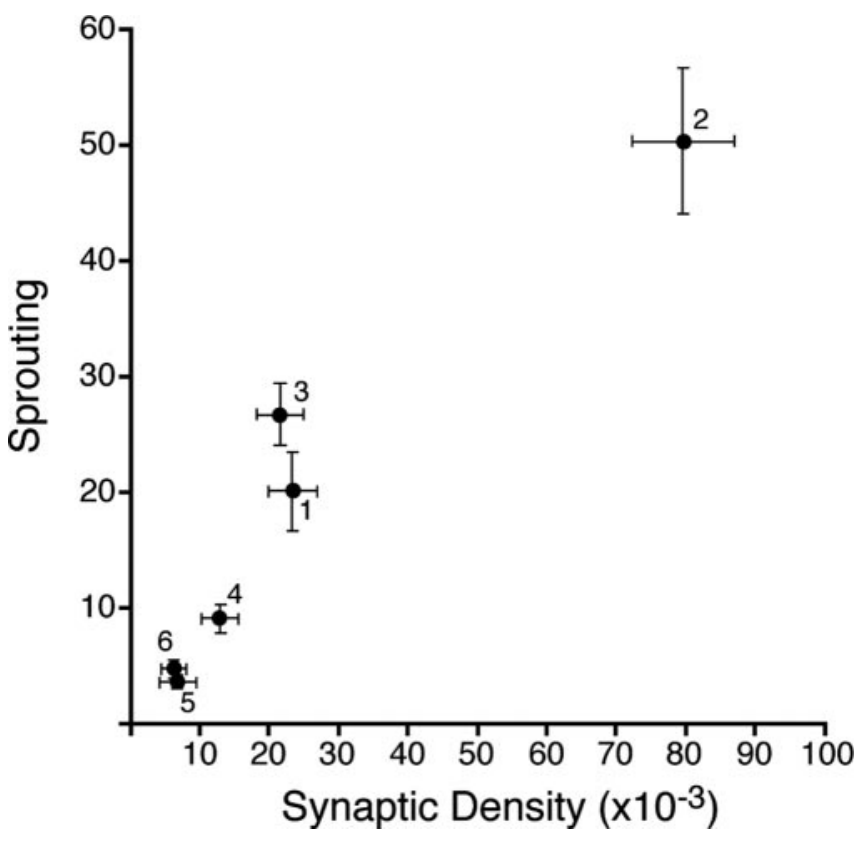

Figure 8. Synapse density is correlated to the amount of sprouting. The increased axon density (a measure of sprouting) (see Materials and Methods) is plotted against the synaptic density measurement for the same various treatment groups described here. This shows a strong correlation between synaptic density and sprouting $\left(r^{2}=0.95\right)$. Note that these two measures were made independently on different slices with different magnification. The groups plotted are as follows: 1, P6 lesion, control L-AP-5 treatment; 2, P6 lesion, AP-5 treatment; 3, P6 lesion, sham Elvax; 4, P6 lesion, NMDA treatment; 5, P11 lesion, control L-AP-5 treatment; 6, P11 lesion, AP-5 treatment.

bility for the age dependence of ipsi axon sprouting. Namely, a general failure to undergo the normal age-dependent downregulation of NMDAR current decay time within the scotoma favored more robust sprouting at the earlier ages examined. Instead, we found that, within the scotoma of P6 lesioned animals, NMDAR currents were actually shorter, not longer, than NMDAR currents in the same colliculus outside the scotoma.

\section{NMDARs and active synaptic depression}

A causal relationship between reductions in anatomically defined synapses and NMDAR activation is consistent with recent evidence that synapse depression, and probably synapse elimination, are active processes fundamental to NMDAR-dependent developmental plasticity (Rittenhouse et al., 1999). Viewing the NMDAR as responsible primarily for arbor elimination rather than elaboration during the initial colonization of a target field is also consistent with much existing data on disrupting NMDAR function during synaptic refinement. For example, NMDAR blockade desegregates retina-specific stripes in the tecta of threeeyed tadpoles by suppressing the synapse elimination that keeps axons of each retina from mixing (Cline et al., 1987). However, after NMDAR blockade, the retinotopic map formed by the contralateral retina in the sSC of rats (Simon et al., 1992) and the tectum of frogs (Cline and Constantine-Paton, 1989) is normal in terms of gross topography and density of arbors; only the removal of topographically inappropriate arbors is prevented. In the ferret lateral geniculate nucleus, retinal ganglion cell (RGC) axons target correct eye-specific lamina and arborize without NMDAR activity, but they fail to restrict their branching to on- and offspecific sublaminar regions (Hahm et al., 1999). In chick tectum, the elimination of ipsilateral RGC axons is reduced by NMDAR blockade (Ernst et al., 1999). In the rodent neocortex, afferent segregation is degraded, although not eliminated, after pharmacological blockade (Schlaggar et al., 1993) or genetic elimination (Iwasato et al., 2000) of the NMDAR, but the afferents continue to grow and make synapses. These studies could not distinguish between the absence of selective stabilization or a specific disturbance of synapse elimination. The present results suggest that the latter process is the mechanism by which NMDAR blockade works during early innervation and helps to explain the relatively normal synapses that are found in these studies, despite their abnormal location. The hypothesis that NMDARs are involved primarily in selective elimination during early developmental plasticity is consistent both with findings that NMDARdependent LTD appears to dominate in several brain regions during early postnatal life (Dudek and Bear, 1993; Feldman et al., 1998; Wasling et al., 2002) and with the demonstrated prominence of LTD in the young sSC after physiologically relevant stimulation (Galli and Maffei, 1988; Lo and Mize, 2002; Mize and Salt, 2004).

\section{References}

Aamodt SM, Shi J, Colonnese MT, Veras W, Constantine-Paton M (2000) Chronic NMDA exposure accelerates development of GABAergic inhibition in the superior colliculus. J Neurophysiol 83:1580-1591.

Artola A, Brocher S, Singer W (1990) Different voltage-dependent thresholds for inducing long-term depression and long-term potentiation in slices of rat visual cortex. Nature 347:69-72.

Bear MF, Rittenhouse CD (1999) Molecular basis for induction of ocular dominance plasticity. J Neurobiol 41:83-91.

Cline HT, Constantine-Paton M (1989) NMDA receptor antagonists disrupt the retinotectal topographic map. Neuron 3:413-426.

Cline HT, Debski EA, Constantine-Paton M (1987) N-methyl-D-aspartate receptor antagonist desegregates eye-specific stripes. Proc Natl Acad Sci USA 84:4342-4345.

Cline HT, Debski EA, Constantine-Paton M (1990) The role of the NMDA receptor in the development of the frog visual system. Adv Exp Med Biol 268:197-203.

Colman H, Nabekura J, Lichtman JW (1997) Alterations in synaptic strength preceding axon withdrawal. Science 275:356-361.

Colonnese MT, Constantine-Paton M (2001) Chronic NMDA receptor blockade from birth increases the sprouting capacity of ipsilateral retinocollicular axons without disrupting their early segregation. J Neurosci 21:1557-1568.

Colonnese MT, Shi J, Constantine-Paton M (2003) Chronic NMDA recep- 
tor blockade from birth delays the maturation of NMDA currents, but does not affect AMPA/kainate currents. J Neurophysiol 89:57-68.

Constantine-Paton M, Cline HT, Debski E (1990) Patterned activity, synaptic convergence, and the NMDA receptor in developing visual pathways. Annu Rev Neurosci 13:129-154.

Cook PM, Prusky G, Ramoa AS (1999) The role of spontaneous retinal activity before eye opening in the maturation of form and function in the retinogeniculate pathway of the ferret. Vis Neurosci 16:491-501.

De Camilli P, Harris Jr SM, Huttner WB, Greengard P (1983) Synapsin I (Protein I), a nerve terminal-specific phosphoprotein. II. Its specific association with synaptic vesicles demonstrated by immunocytochemistry in agarose-embedded synaptosomes. J Cell Biol 96:1355-1373.

Dudek SM, Bear MF (1993) Bidirectional long-term modification of synaptic effectiveness in the adult and immature hippocampus. J Neurosci 13:2910-2918.

Ernst AF, Wu HH, El-Fakahany EE, McLoon SC (1999) NMDA receptormediated refinement of a transient retinotectal projection during development requires nitric oxide. J Neurosci 19:229-235.

Feldman DE, Nicoll RA, Malenka RC, Isaac JT (1998) Long-term depression at thalamocortical synapses in developing rat somatosensory cortex. Neuron 21:347-357.

Finlay BL, Wilson KG, Schneider GE (1979) Anomalous ipsilateral retinotectal projections in Syrian hamsters with early lesions: topography and functional capacity. J Comp Neurol 183:721-740.

Fox K, Schlaggar BL, Glazewski S, O'Leary DD (1996) Glutamate receptor blockade at cortical synapses disrupts development of thalamocortical and columnar organization in somatosensory cortex. Proc Natl Acad Sci USA 93:5584-5589.

Frost DO, Schneider GE (1979) Plasticity of retinofugal projections after partial lesions of the retina in newborn Syrian hamsters. J Comp Neurol 185:517-567.

Galli L, Maffei L (1988) Spontaneous impulse activity of rat retinal ganglion cells in prenatal life. Science 242:90-91.

Gundersen HJ (1986) Stereology of arbitrary particles. A review of unbiased number and size estimators and the presentation of some new ones, in memory of William R. Thompson. J Microsc 143:3-45.

Hahm JO, Langdon RB, Sur M (1991) Disruption of retinogeniculate afferent segregation by antagonists to NMDA receptors. Nature 351:568-570.

Hahm JO, Cramer KS, Sur M (1999) Pattern formation by retinal afferents in the ferret lateral geniculate nucleus: developmental segregation and the role of $N$-methyl-D-aspartate receptors. J Comp Neurol 411:327-345.

Hopf FW, Waters J, Mehta S, Smith SJ (2002) Stability and plasticity of developing synapses in hippocampal neuronal cultures. J Neurosci 22:775-781.

Huerta MF, Harting JK (1984) The mammalian superior colliculus: studies of its morphology and connections. In: Comparative neurology of the optic tectum (Vanegas H, ed), pp 687-773. New York: Plenum.

Iwasato T, Datwani A, Wolf AM, Nishiyama H, Taguchi Y, Tonegawa S, Knopfel T, Erzurumlu RS, Itohara S (2000) Cortex-restricted disruption of NMDAR1 impairs neuronal patterns in the barrel cortex. Nature 406:726-731.

Jeon CJ, Hartman MK, Mize RR (1997) Glutamate-like immunoreactivity in the cat superior colliculus and visual cortex: further evidence that glutamate is the neurotransmitter of the corticocollicular pathway. Vis Neurosci 14:27-37.

Katz LC, Shatz CJ (1996) Synaptic activity and the construction of cortical circuits. Science 274:1133-1138.

Korkotian E, Segal M (2001) Regulation of dendritic spine motility in cultured hippocampal neurons. J Neurosci 21:6115-6124.

Lo FS, Mize RR (2002) Properties of LTD and LTP of retinocollicular synaptic transmission in the developing rat superior colliculus. Eur J Neurosci 15:1421-1432.

Lopez-Medina A, Bueno-Lopez JL, Reblet C (1989) Postnatal development of the occipito-tectal pathway in the rat. Int J Dev Biol 33:277-286.

Lund RD (1965) Uncrossed visual pathway of hooded and albino rats. Science 149:1506-1507.

Lund RD (1969) Synaptic patterns of the superficial layers of the superior colliculus of the rat. J Comp Neurol 135:179-208.
Lund RD, Lund JS (1973) Reorganization of the retinotectal pathway in rats after neonatal retinal lesions. Exp Neurol 40:377-390.

Lund RD, Lund JS (1976) Plasticity in the developing visual system: the effects of retinal lesions made in young rats. J Comp Neurol 169:133-154.

Malinow R, Malenka RC (2002) AMPA receptor trafficking and synaptic plasticity. Annu Rev Neurosci 25:103-126.

Mize RR (1988) Immunocytochemical localization of $\gamma$-aminobutyric acid (GABA) in the cat superior colliculus. J Comp Neurol 276:169-187.

Mize RR, Salt TE (2004) Contribution of GABAergic inhibition to synaptic responses and LTD early in postnatal development in the rat superior colliculus. Eur J Neurosci 20:1331-1340.

Nishiyama M, Hong K, Mikoshiba K, Poo MM, Kato K (2000) Calcium stores regulate the polarity and input specificity of synaptic modification. Nature 408:584-588.

O'Leary DD, Cowan WM (1983) Topographic organization of certain tectal afferent and efferent connections can develop normally in the absence of retinal input. Proc Natl Acad Sci USA 80:6131-6135.

Pinches EM, Cline HT (1998) Distribution of synaptic vesicle proteins within single retinotectal axons of Xenopus tadpoles. J Neurobiol $35: 426-434$.

Rittenhouse CD, Shouval HZ, Paradiso MA, Bear MF (1999) Monocular deprivation induces homosynaptic long-term depression in visual cortex. Nature 397:347-350.

Sather W, Dieudonne S, MacDonald JF, Ascher P (1992) Activation and desensitization of $N$-methyl-D-aspartate receptors in nucleated outsideout patches from mouse neurones. J Physiol (Lond) 450:643-672.

Schlaggar BL, Fox K, O’Leary DD (1993) Postsynaptic control of plasticity in developing somatosensory cortex. Nature 364:623-626.

Shi J, Aamodt SM, Constantine-Paton M (1997) Temporal correlations between functional and molecular changes in NMDA receptors and GABA neurotransmission in the superior colliculus. J Neurosci 17:6264-6276.

Shi J, Aamodt SM, Townsend M, Constantine-Paton M (2001) Developmental depression of glutamate neurotransmission by chronic low-level activation of NMDA receptors. J Neurosci 21:6233-6244.

Silver MA, Stryker MP (1999) Synaptic density in geniculocortical afferents remains constant after monocular deprivation in the cat. J Neurosci 19:10829-10842.

Silver MA, Stryker MP (2000) A method for measuring colocalization of presynaptic markers with anatomically labeled axons using double label immunofluorescence and confocal microscopy. J Neurosci Methods 94:205-215.

Simon DK, Prusky GT, O’Leary DD, Constantine-Paton M (1992) $\mathrm{N}$-methyl-D-aspartate receptor antagonists disrupt the formation of a mammalian neural map. Proc Natl Acad Sci USA 89:10593-10597.

Simon DK, Roskies AL, O'Leary DD (1994) Plasticity in the development of topographic order in the mammalian retinocollicular projection. Dev Biol 162:384-393.

Smith AL, Cordery PM, Thompson ID (1995) Manufacture and release characteristics of Elvax polymers containing glutamate receptor antagonists. J Neurosci Methods 60:211-217.

Stent GS (1973) A physiological mechanism for Hebb's postulate of learning. Proc Natl Acad Sci USA 70:997-1001.

Thompson I, Holt C (1989) Effects of intraocular tetrodotoxin on the development of the retinocollicular pathway in the Syrian hamster. J Comp Neurol 282:371-388.

van den Pol AN, Obrietan K, Belousov AB, Yang Y, Heller HC (1998) Early synaptogenesis in vitro: role of axon target distance. J Comp Neurol 399:541-560.

Warton SS, McCart R (1989) Synaptogenesis in the stratum griseum superficiale of the rat superior colliculus. Synapse 3:136-148.

Wasling P, Hanse E, Gustafsson B (2002) Long-term depression in the developing hippocampus: low induction threshold and synapse nonspecificity. J Neurosci 22:1823-1830.

Wiedenmann B, Franke WW (1985) Identification and localization of synaptophysin, an integral membrane glycoprotein of Mr 38,000 characteristic of presynaptic vesicles. Cell 41:1017-1028.

Zhu JJ, Malinow R (2002) Acute versus chronic NMDA receptor blockade and synaptic AMPA receptor delivery. Nat Neurosci 5:513-514. 